\title{
Lamellar Tetragonal Symmetry of Amphiphilic Thermotropic Ionic Liquid Crystals in the Framework of Other Closely Related Highly Ordered Structures
}

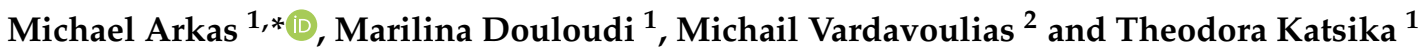 \\ 1 Demokritos National Centre for Scientific Research, Institute of Nanoscience and Nanotechnology, \\ 15310 Athens, Greece; marilina.douloudi@gmail.com (M.D.); theodorakatsika@gmail.com (T.K.) \\ 2 PYROGENESIS S.A., Technological Park 1, Athinon Avenue, 19500 Lavrion, Greece; \\ mvardavoulias@pyrogenesis-sa.gr \\ * Correspondence: m.arkas@inn.demokritos.gr; Tel.: +30-210-650-3669
}

check for updates

Citation: Arkas, M.; Douloudi, M.;

Vardavoulias, M.; Katsika, T.

Lamellar Tetragonal Symmetry of

Amphiphilic Thermotropic Ionic

Liquid Crystals in the Framework of

Other Closely Related Highly

Ordered Structures. Symmetry 2022,

14, 394. https://doi.org/10.3390/

sym14020394

Academic Editor: György Keglevich

Received: 27 January 2022

Accepted: 14 February 2022

Published: 16 February 2022

Publisher's Note: MDPI stays neutral with regard to jurisdictional claims in published maps and institutional affiliations.

Copyright: () 2022 by the authors Licensee MDPI, Basel, Switzerland. This article is an open access article distributed under the terms and conditions of the Creative Commons Attribution (CC BY) license (https:// creativecommons.org/licenses/by/ $4.0 /)$.

\begin{abstract}
An overview of the chemical compounds forming the rare smectic $\mathrm{T}$ phases is presented with references to the historical context. Thermodynamics (transition temperatures, enthalpies) along with the factors (stereochemical constraints, electrostatic interactions, aliphatic chain stacking, intermolecular forces) contributing to the adoption of tetragonal scaffolds are also discussed. Characteristic optical microscopy textures and X-ray diffraction patterns are presented. In parallel, a comparison of the geometrical parameters such as distances between atoms, molecular areas, volumes, and lattice parameters with the closest two-dimensional and three-dimensional organizations, is performed.
\end{abstract}

Keywords: smectic T; lamellar; tetragonal symmetry; liquid crystals; square lattice; lattice parameter; thermotropic; two-dimensional organization; 2D positional order; quaternary ammonium

\section{Introduction}

Thermotropic liquid crystals [1] are an anisotropic liquid state of matter [2,3]. The molecules of a solid retain their orientation through the increase in temperature, to meet an average orientation, the director $\tilde{n}$, (orientational order) whereas their position according to a three-dimensional lattice (positional order) is compromised [4-6]. The formation and stabilization of mesophases are governed by the microsegregation of incompatible moieties, such as hydrophilic and lipophilic groups, flexible and rigid parts, and the aggregation of fragments bearing the same property [7-9]. Furthermore, electrostatic and hydrophobic interactions between polar and non-polar functionalities, respectively; hydrogen bonding [10-14], dipole-dipole interactions [15], van der Waals interactions [16] $\pi-\pi$ stacking [17] and doping with heterogeneous materials [18] play a vital role.

The arrangement of liquid crystals in mesophases with tetragonal symmetry is not very common. Phases with an orientational order (Nematic [19], Columnar Nematic [20], and cholesteric [21]) and positional order in one dimension (Smectic A [22], Smectic C [23]) are entropically favored. Nature hates voids. In the absence of specific reasons [24], (homonymous charge repulsion, intermolecular and intramolecular forces, stereochemical constraints) van der Waals interactions prompt the mesogens to organize so that they are as densely packed as possible. Symmetric parts of similar size or moieties that cover similar spaces due to their thermal movement preferentially form hexagonal phases (Smectic B [25], Smectic F [26], Smectic I [27], columnar hexagonal [28]) in proximity with six first neighboring unities. This behavior complies with identical principles prevailing in the formation of solid organic crystals [29]. Distortion of the hexagonal symmetry produces rectangular two-dimensional lattices (Smectic E [30], columnar rectangular [31]) and respective $3 \mathrm{D}$ orthogonal (smectic $\mathrm{K}$ [32]). When conditions for square symmetry are 
fulfilled cubic lattices are usually generated [33]. Thus, it is sensible that such phases are rare and in many instances, unstable.

There are some cases of discotic mesophases reported in the scientific bibliography exhibiting tetragonal symmetry. Most of them are formed by macromolecules such as complexes of anionic lipids with cationic dendronized polymers (Figure 1a) [34]. Elongated molecules with $\pi$-conjugated rigid aromatic cores polycatenar oligothiophenes for instance possess a tendency to assemble in tetragonally ordered columns squares as well (Figure 1b) [35]. Of particular interest are photoluminescent dendrimers with a 2,6-diethynylanthracene core that are stimuli-responsive and undergo a transition from the cubic state to the columnar tetragonal by mechanical shearing (Figure 1c,d) [36,37].

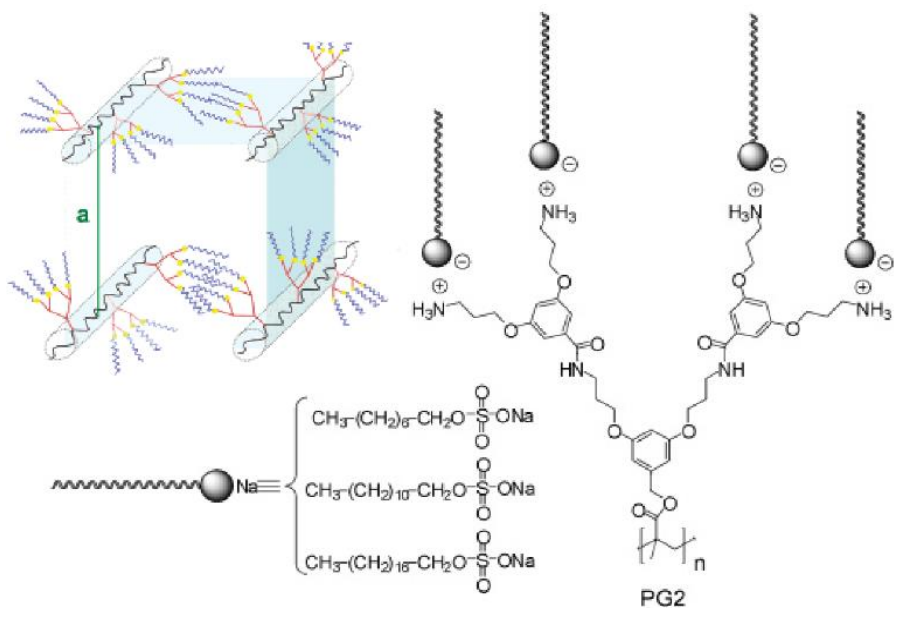

(a)
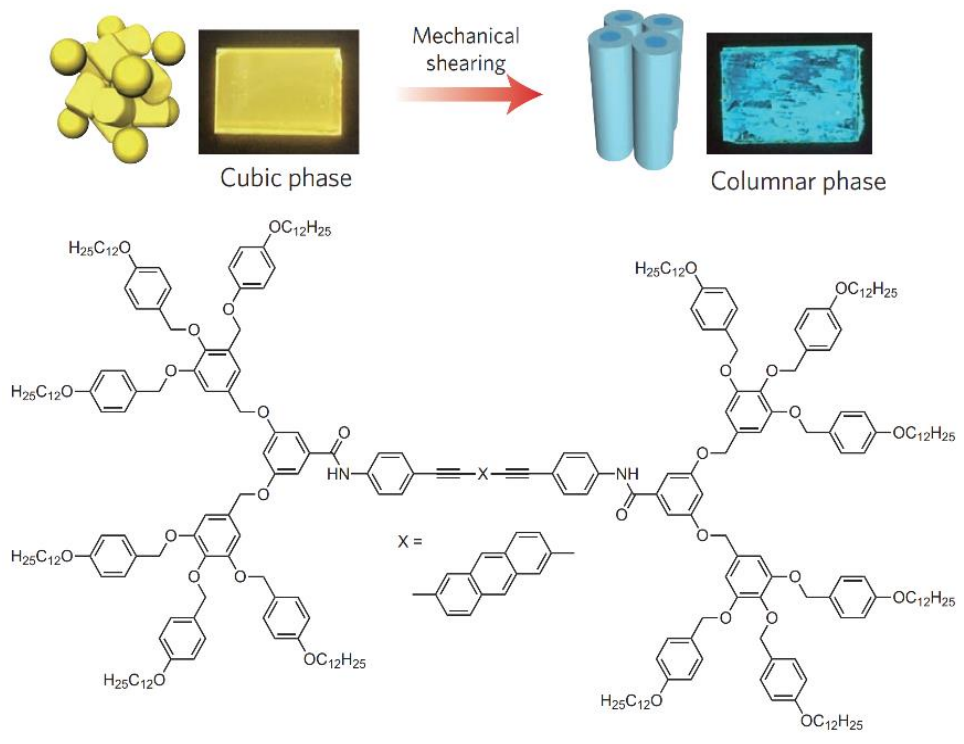

(c)

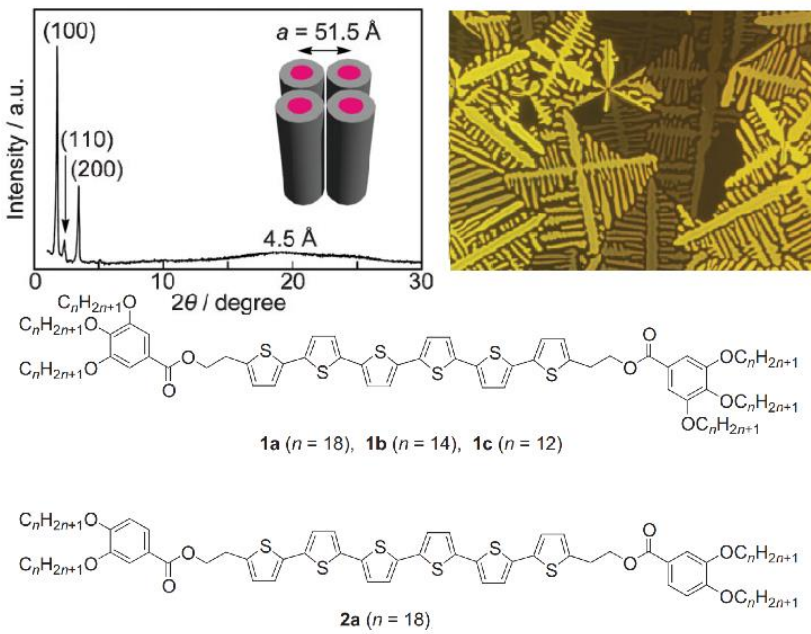

(b)

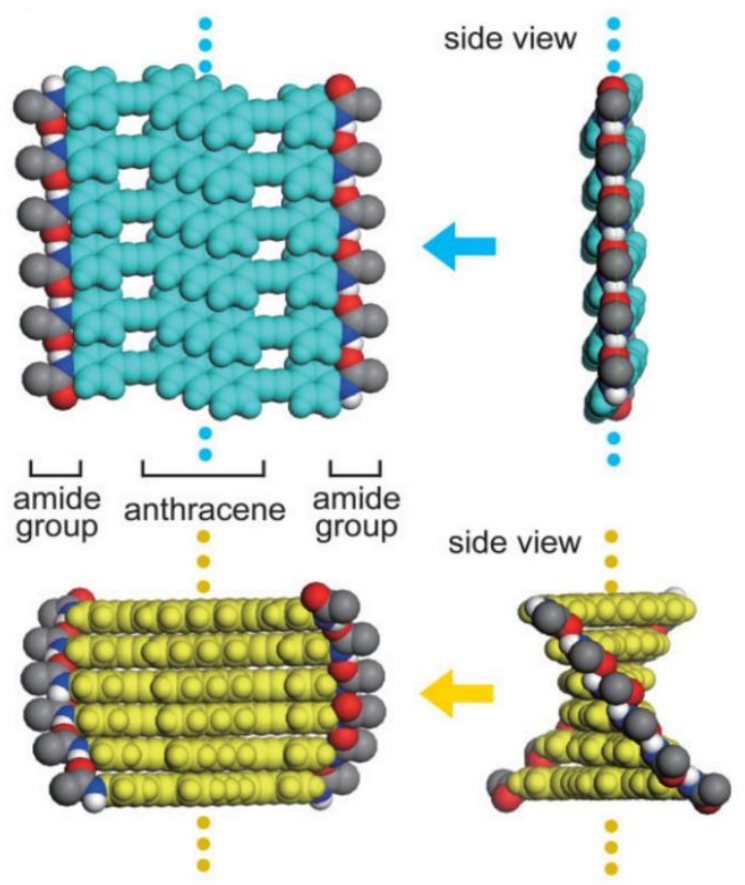

(d)

Figure 1. (a) Complexes of the second generation dendronized polymers and surfactants and schematic 
representation of tetragonal columnar phase. Reproduced with permission from [34]. Green "a" symbolizes the lattice parameter of the tetragonal symmetry; (b) X-ray Diffraction patterns and polarized optical photomicrographs of columnar tetragonal organization, formed by polycatenar oligothiophenes. Reproduced with permission from [35]; (c) Piezochromic luminescence shift due to the transition of the photoluminescent dendrimer from the cubic phase to the columnar tetragonal by mechanical shearing. Reproduced with permission from [37]; (d) Molecular model of the dendrimer's structure in the columnar phase (top) and the cubic phase (bottom). The dendritic side chains are abbreviated. Reproduced with permission from [36].

Calamitic molecules may form lamellar tetragonal phases as well. One such early example is a monotropic phase detected from the mosaic optical texture for the hexadecyl and octadecyl derivatives of $4^{\prime}$-n-Alkyloxy-3'-nitro-biphenyl carboxylic acids 1 (Figure 2a) and was named $S_{4}$ [38]. It occurs when the compounds are heated well beyond the transition into the isotropic state and then subsequently cooled from the smectic A phase at $195^{\circ} \mathrm{C}$. It is quickly transformed to the well-known cubic Smectic D cubic organization at $191{ }^{\circ} \mathrm{C}$. The $3 \mathrm{D}$ tetragonal $\mathrm{I}_{1} /$ /acd symmetry was demonstrated for silver(I) complexes with alkoxystilbazoles 2 (Figure 2a) [39] and was established by a posterior comparative study along with a non-ionic system with an aromatic core of two biphenyls bonded by an ester group and bearing two terminal branched chains, one chiral and one nonchiral 3 (Figure 2a) [40].

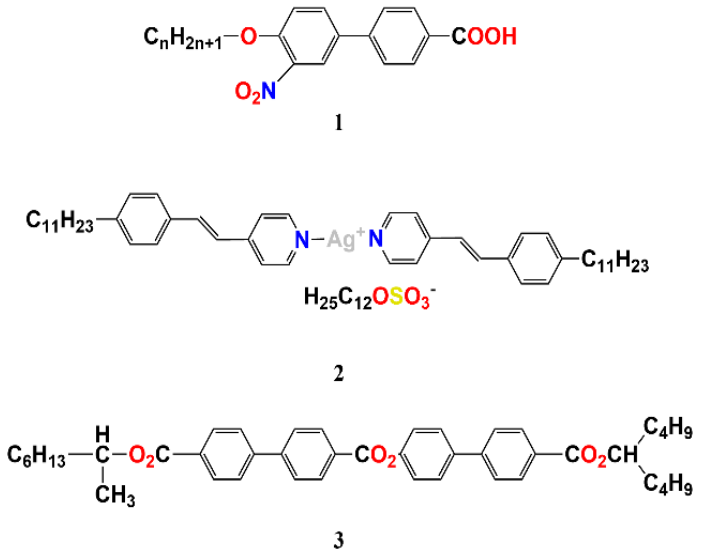

(a)

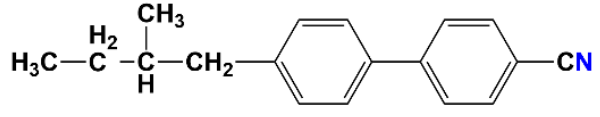

CB15
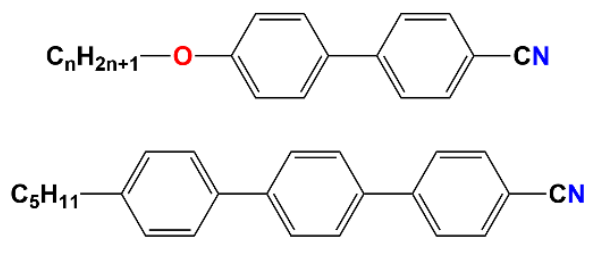

E9

(b)

Figure 2. (a) Chemical formulas of molecules that form the $3 \mathrm{D}$ tetragonal $\mathrm{S}_{4}$ phase; (b) Chemical formulas of 4-cyano-4'-(2-methyl)butyl-biphenyl (CB15) and of the eutectic E9 (4-cyano-4'-(n-alkoxy) biphenyls and 4-cyano-4'-(n-pentyl) triphenyl).

Another unstable three-dimensional tetragonal phase has been observed in mixtures of chiral 4-cyano-4'-(2-methyl)butyl-biphenyl (CB15) in a eutectic mixture of three or more 4-cyano-4'-(n-alkoxy) biphenyls and 4-cyano-4'-(n-pentyl) triphenyl (E9) by an electric-fieldinduced structural transition from frustrated cubic blue phase (Figure 2b) [41-43]. Stable tetragonal organizations are observed in a variety of inflexible aromatic core mesogens functionalized by long aliphatic chains, and "rod-coil" molecules [44].

Apart from these above-described categories of rigid "molecular" mesogens, ionic liquid crystals; mostly amphiphilic flexible entities resulting from the introduction of ionic parts to hydrophobic moieties [45-48], also form tetragonal phases commonly termed as smectic T. The object of the present work is the comparative presentation of these latter lamellar organizations that are assembled from amphiphilic molecules bearing cationic head groups containing nitrogen (quaternary ammonium, piperazinium, pyrrolidinium, piperidinium, imidazolium, pyridinium). Two-dimensional or 3D ionic square planes are formed by the polar sublayers where the positively charged ions together with their counterions are placed perpendicular to the smectic layers. In these hydrophobic parts, 
flexible aliphatic chains have a characteristic positional short-range order, orientational long-range order along the average direction of the long molecular axes, the director, and a 1D-translational long-range order along with the normal layer [49].

\section{Quaternary Ammonium Salts}

Alami et al. reported lamellar amphiphilic ionic liquid crystals with tetragonal symmetry for the first time and proposed the symbol $S_{\mathrm{T}}$ [50]. It was detected in a series of $\mathrm{N}, \mathrm{N}$, dialkyl dimethyl quaternary ammonium bromide salts with two long alkyl chains (Figure 3). The smectic periods, calculated from the three to five equidistant sharp Bragg reflections in the small-angle region, grow linearly as a function of the total number of carbon atoms of the two long chains. The thickness of the ionic lattice calculated by the Y-intercept (1.31 $\AA$ ) was verified by the fact that the intensity of the harmonics decreases slowly as the diffraction angles increase. This means that the strongly diffracting heavy bromine ions are localized in thin layers less than $5 \AA$. The three peaks at the wide-angle region are typical of the three main reflections $(1,1),(2,0)$, and $(2,1)$ of a two-dimensional tetragonal order with a lattice parameter $a=6.04 \AA$. The molecular area calculated from the linear dependence of lamellar periods as a function of the carbon atoms is $37.6 \AA^{2}$ almost equal to the square of the lattice parameter, meaning that only one molecule is present per unit cell (space group $\mathrm{P} 4$ or $\mathrm{P} 4 \mathrm{~m}$ ). The spherical bromide ions are positioned at the corners of the unit cell and the tetramethyl(ene) ammonium ions are at the center of the square lattice (Figure $4 a, b)$. The authors related the formation of this tetragonal symmetry to the ionic groups that interact through electrostatic forces, of one or even two orders of magnitude stronger than van der Waals or dipolar forces. Homonymous charges are repulsed and tend to remain as far as possible from one another, while heteronymous charges are attracted and are in close contact to counterbalance charge differences. The square arrangement favors the optimal alternation of negative and positive charges when there are in equal numbers. As a consequence, several ionic systems with two-dimensional positional order adopt tetragonal symmetry. The results on the existence of this new phase were verified by Przedmojski et al. for dihexadecyl and dioctadecyl dimethyl ammonium bromides [51].

An initial modification of this category of quaternary ammonium bromides was performed via the replacement of one of the two long alkyl chains with a shorter spacer bearing three carbon atoms and a cyano group at the end [52]. The latter are strong dipoles and tend to cause dimerization due to antiferroelectric association. The molecular areas in the solid-state measured by dilatometry $\left(S=38.4 \pm 0.2 \AA^{2}\right)$, and calculated from the $\mathrm{Y}$ intercepts of the lamellar periods as previously $\left(S=37.0 \pm 1.5 \AA^{2}\right)$ are very close to the value of the smectic $\mathrm{T}$ phase $\left(37.6 \AA^{2}\right)$. The harmonic lamellar reflections intensity, however, does not decrease monotonically as a function of the diffraction angle. It oscillates sinusoidally reaching zero at angles corresponding to spacings in the range from 0.075 to $0.090 \AA$. The bromine ions are thus not located in a single layer. They form two distinct ionic planes in combination with ammonium cations and are separated by the cyanopropyl groups. The distance between these two lamellae calculated from the intensity distribution curve first minimum was $6.1 \AA$. Since molecular areas are the same, assuming the 2D tetragonal symmetry is similar to that observed for the smectic T phase of the N, alkyl N, alkyl N, N, dimethyl quaternary ammonium bromides we conclude to an almost cubic three-dimensional sub-cell ( $a=b=6.2 \AA c=6.1 \AA$ ). Yet, although these salts "melt" at about the same temperature range as their dialkyl ammonium predecessors, this $3 \mathrm{D}$ positional order transforms into a one-dimensional smectic A phase. Further efforts to loosen the severe geometrical constraints induced by the coupling of the cyano groups by increasing the spacer length or to preserve the solid 3D organization to the liquid crystalline state by shortening the cyano-alkyl chain did not generate tetragonal assembly [53]. Larger declinations are produced within the molecular areas in the solid-state (43 to $51 \AA^{2}$ ) when cyano groups are replaced by functionalities forming hydrogen bonds. Terminal hydroxy 6 and carboxy 7 (Figure 3) groups tend to induce a tilt (24-39 degrees) of the alkyl chains 
even if an interdigitated organization in a single layer is considered. Furthermore, only thermotropic smectic A phases are observed [54].
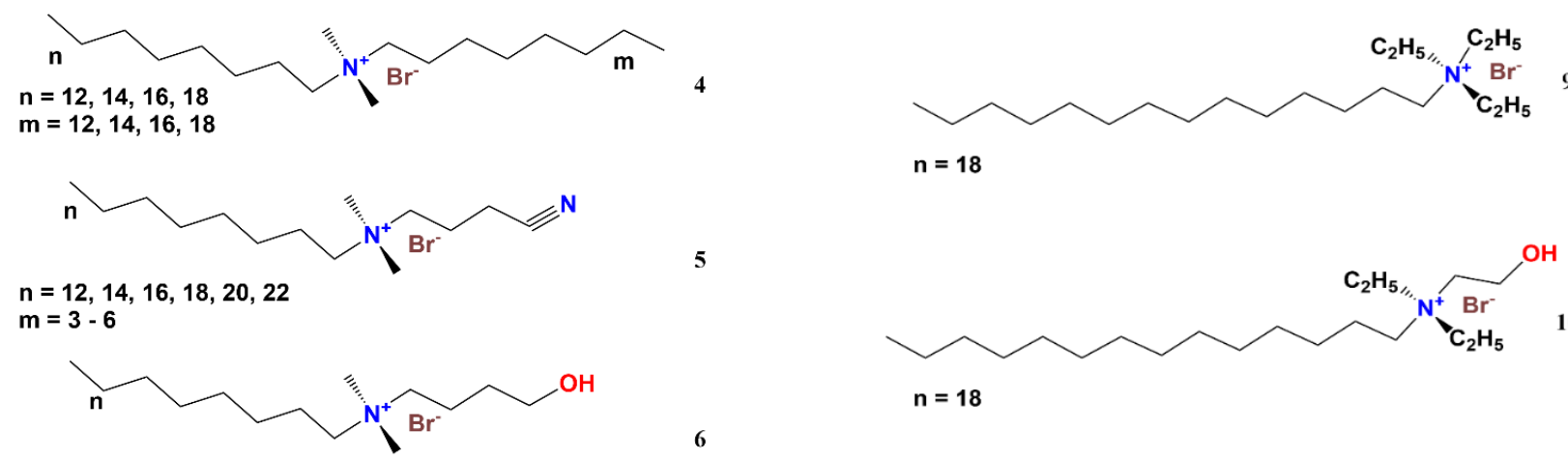

5

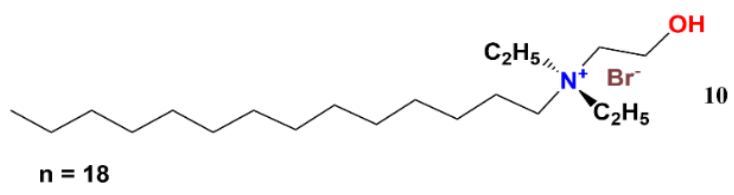

$\mathrm{n}=12,14,16,18$

$\mathrm{m}=1,5$
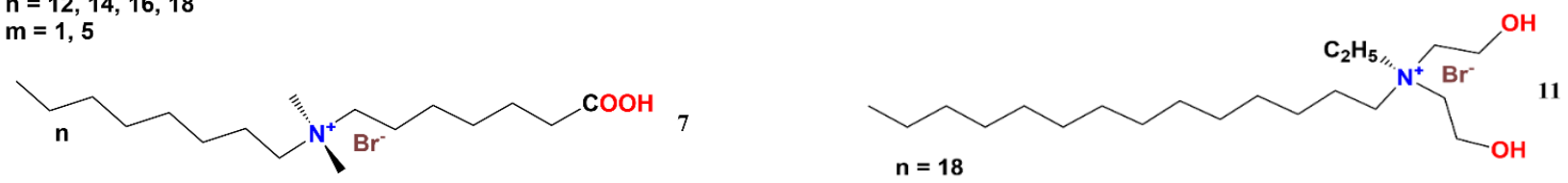

$\mathrm{n}=12,14,16,18$

$\mathrm{m}=2,3,6,10$
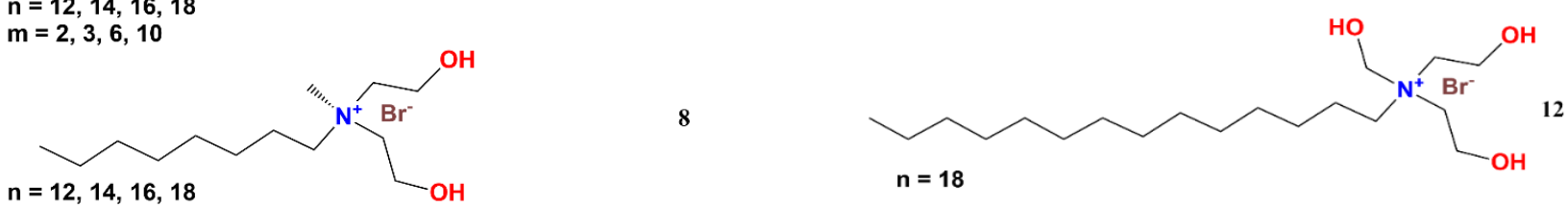

Figure 3. Chemical formulas of N, N, dialkyl N, N, dimethyl quaternary ammonium bromides (4), N alkyl, N, cyanopropyl, N, N, dimethyl ammonium bromides (5), N alkyl, N, hydroxyalkyl, N, N, dimethyl ammonium bromides (6), N alkyl, N, carboxyalkyl, N, N, dimethyl ammonium bromides (7), N alkyl, N, N, hydroxyethyl, N, methyl ammonium bromides (8) N, N, N, triethyl octadecyl ammonium bromide (9), N, N, diethyl, N, hydroxyethyl octadecyl ammonium bromide (10), N, N, dihydroxy ethyl, N, ethyl, octadecyl ammonium bromide (11), N, N, trihydroxy ethyl, octadecyl ammonium bromide (12).

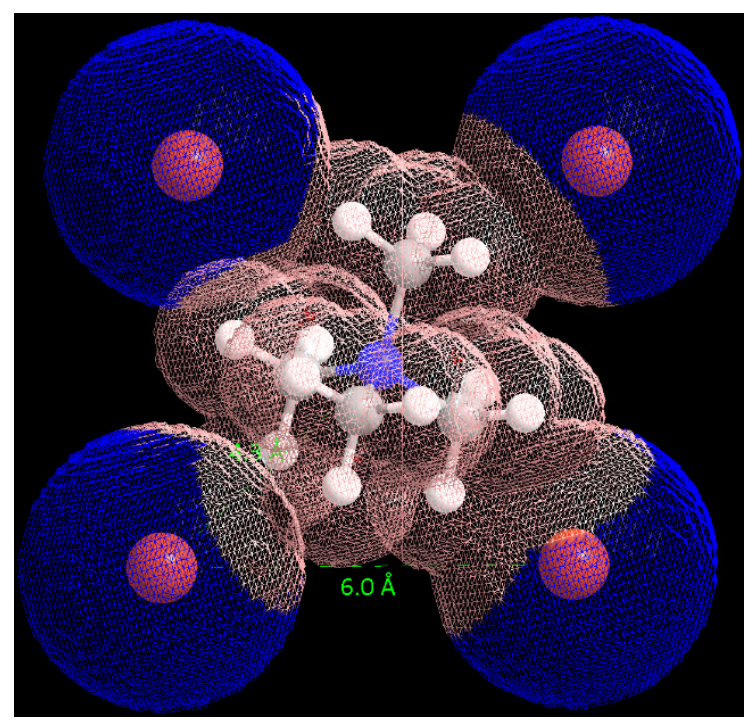

(a)

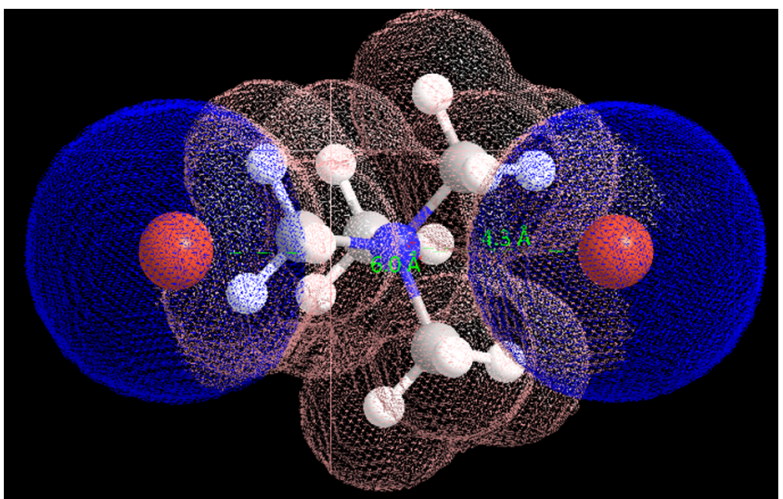

(b)

Figure 4. Top (a) and side (b) view of the organization and positive (red) and negative (blue) charge distribution of the tetragonal polar sublattice of $\mathrm{N}, \mathrm{N}$, dimethyl quaternary ammonium bromide salts. 
When two hydroxyethyl alkyl chains are attached to the nitrogen atom 8 (Figure 3) the tilt of the long aliphatic chains is even larger at room temperature $\left(46^{\circ}\right)$ leading to molecular areas of $56 \AA^{2}$, which are inappropriate for a tetragonal mesophase [55]. Yet, by increasing temperature and providing both energy and movement capacity to the moieties that form the soft lipophilic layer, these extreme values are compromised by a transition to an intermediate crystalline phase $\left(\mathrm{K}_{2}\right)$ with a $36^{\circ}$ tilt and molecular areas of $48.54 \AA^{2}$. The latter corresponds to a theoretical tetragonal arrangement with $a=6.96 \AA$. This lattice parameter seems, at first, very large $(15 \%)$ for the $\mathrm{N}^{+}-\mathrm{Br}^{-}$ion pairs arrangement in squares. Surprisingly though, the X-ray's pattern of the first mesophase is characteristic of the smectic T phase. Interestingly, the lattice parameter of the tetragonal unit cell $(6.96 \AA)$ is the same as that theoretically predicted for the former intermediate crystalline phase. Moreover, the thickness of the polar sublayers in the smectic T calculated from the Y-intercept of the lamellar periods (d) versus the number of carbon atoms (n) is the same as the respective width of the $\mathrm{K}_{2}$ phase $(9.8 \AA$ ). It is profound, that even though the carbon chains are molten in the smectic T mesophase, the tetragonal ionic sublattice of the $K_{2}$ crystalline phase is preserved completely intact. An explanation is still needed for the discord of the large lattice surface $\left(48.54 \AA^{2}\right)$. This value is excessive for a conventional smectic aliphatic chain stacking ( $37.6 \AA^{2}$ ) that was also adopted for the smectic T configuration $\mathrm{N}$, N, dimethyl quaternary ammonium bromide salts with two long alkyl chains. Calculation of the number $\mathrm{Z}$ of molecules per tetragonal unit cell performed based on the known value methylene volume at the respective temperature $\left(\mathrm{V}_{\mathrm{CH} 2}=27.8 \AA^{3}\right.$ at $\left.90{ }^{\circ} \mathrm{C}[56]\right)$ revealed $\mathrm{Z}=2$ instead of one in the standard $\mathrm{N}+-\mathrm{Br}^{-}$square lattices. Thus, since there is not enough space for the ammonium and bromine ions to be juxtaposed in single layers (75 against $48.54 \AA^{2}$ ) they are superposed one atop the other in double layers (Figure 5a,b). The larger area of the tetragonal configuration has an immediate effect on the configuration of the molten alkyl chains since in this instance there is enough space for them to be interdigitated $\left(2 \times 24=48 \AA^{2}\right.$ [56]) in contrast to the dialkyl derivatives that were arranged in double layers (Figure 6a,b).

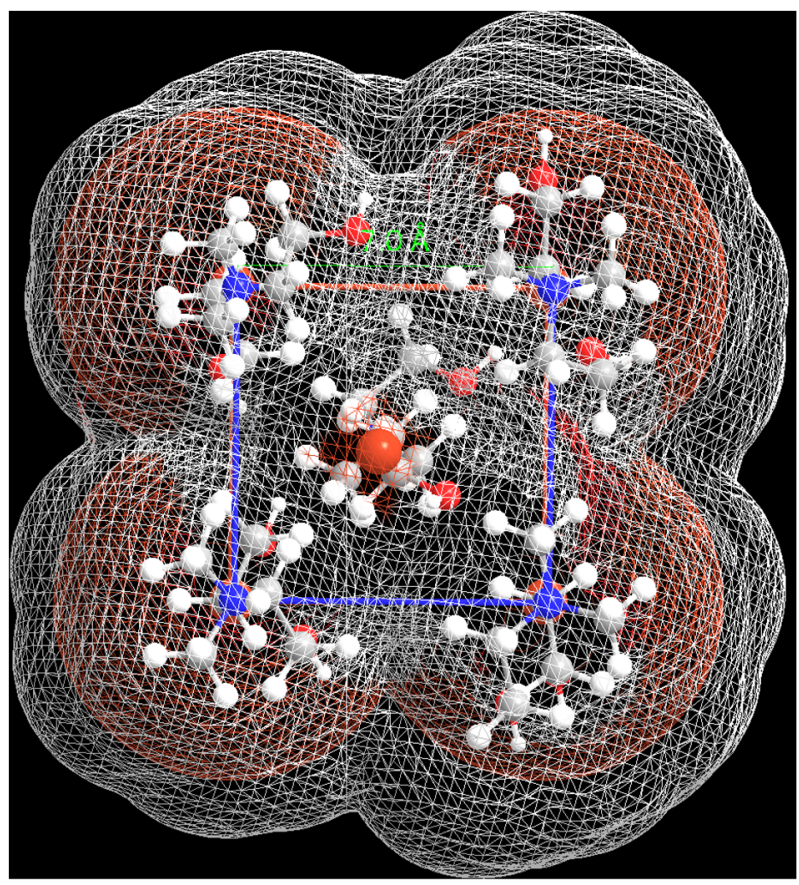

(a)

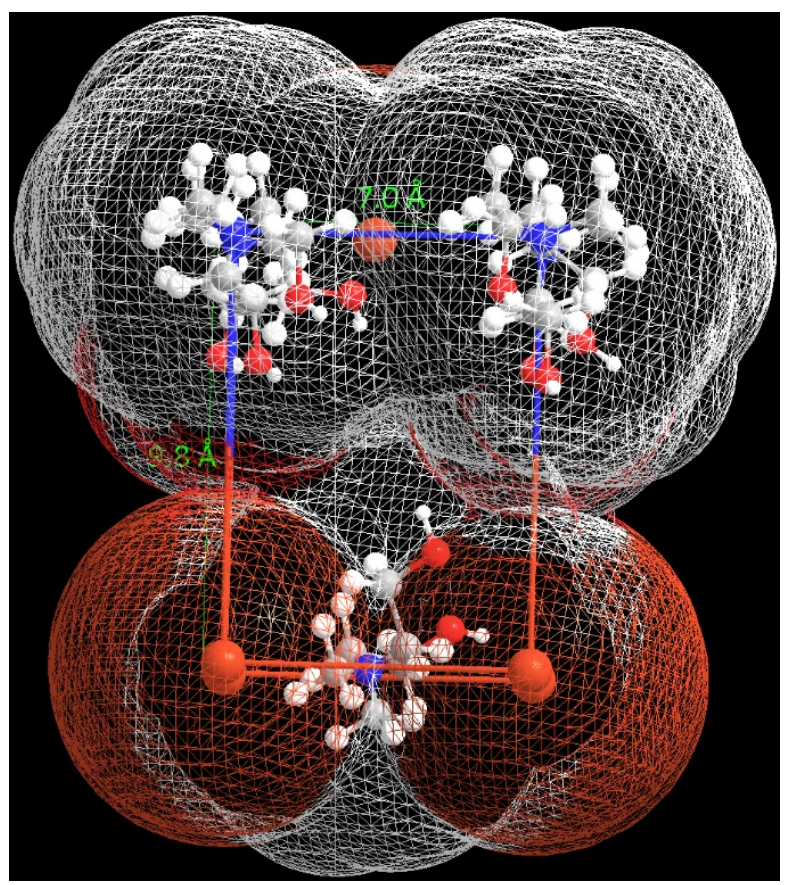

(b)

Figure 5. Top (a) and side (b) views of the organization of the tetragonal polar sublattice of dihydroxyethyl quaternary ammonium bromides. 


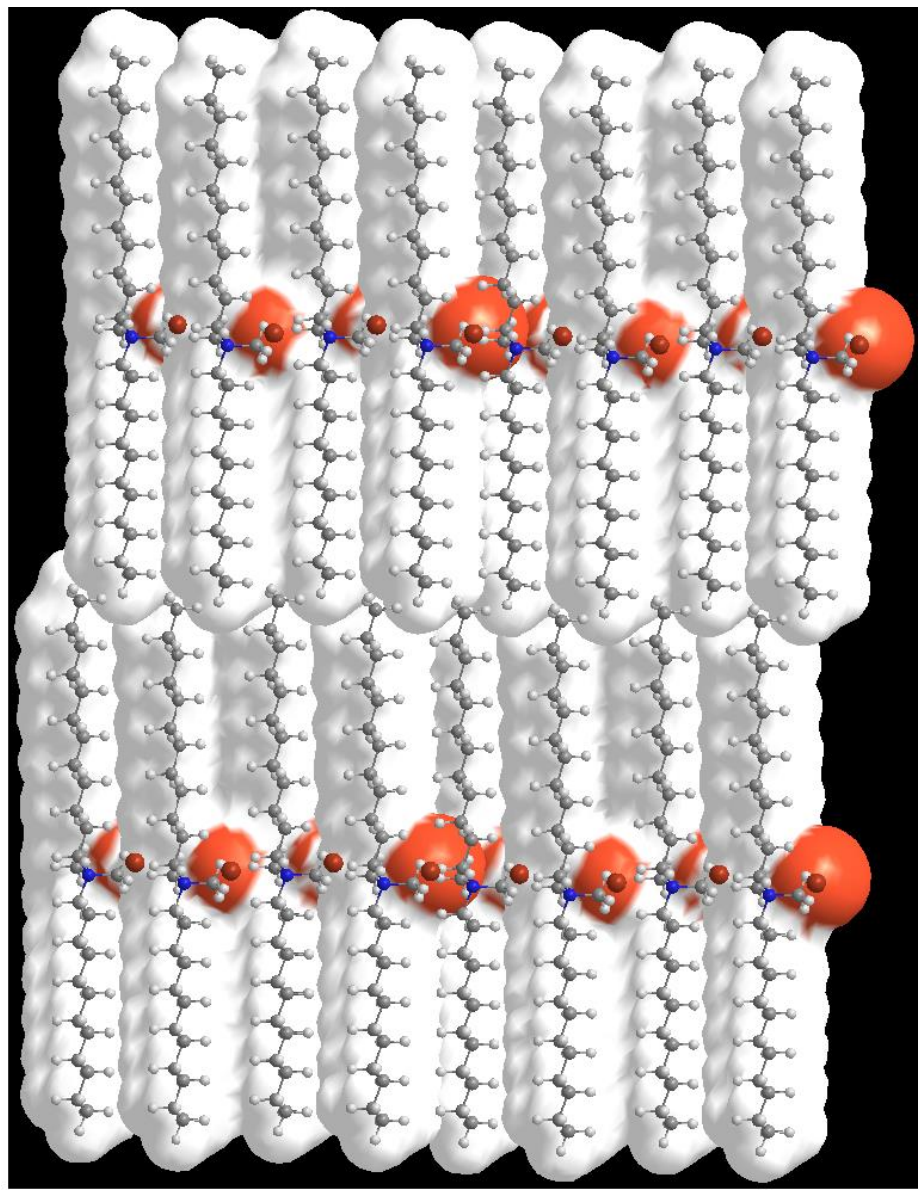

(a)

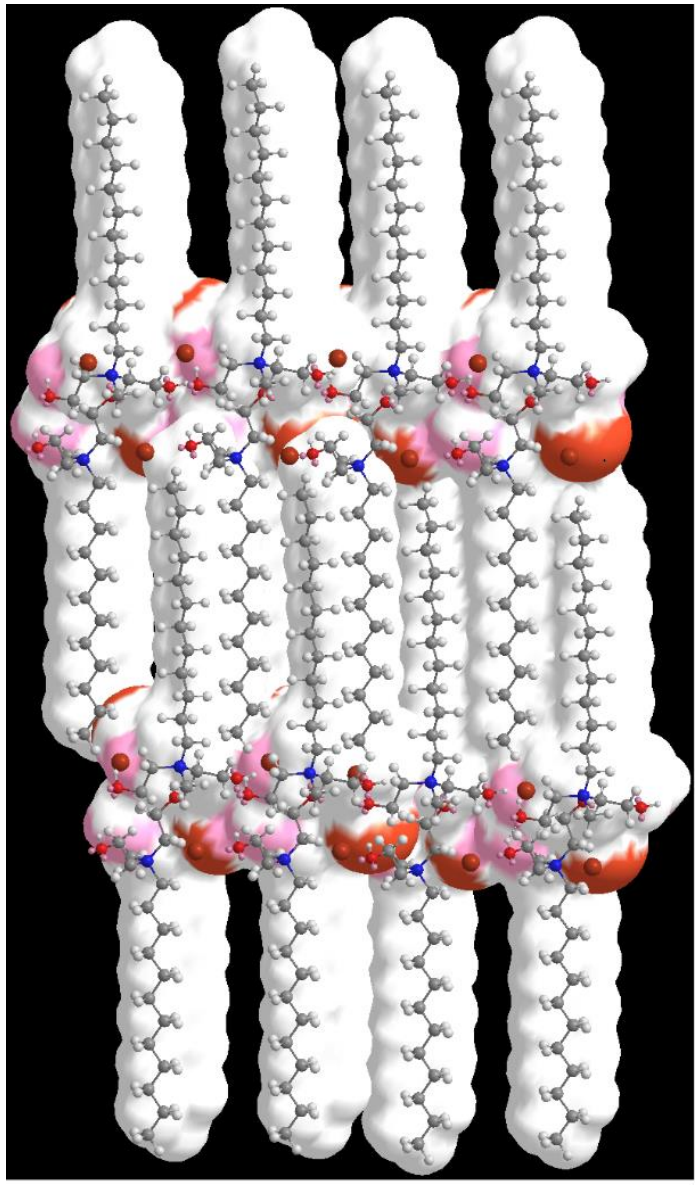

(b)

Figure 6. Structural models of aliphatic chain organization in the smectic $\mathrm{T}$ phase (a) in double layers in for $\mathrm{N}, \mathrm{N}$, dialkyl N, N, dimethyl quaternary ammonium bromides; (b) Interdigitated in single layers for $\mathrm{N}$, alkyl, $\mathrm{N}, \mathrm{N}$ dihydroxyl, $\mathrm{N}$ methyl ammonium bromides.

An obvious and very compelling path to by which to conduct research on this particular sub-field is to change the cation size by selecting ethyl ammonium polar heads at the place of the conventional methylammonium, and study one further parameter, i.e., the number of the attached hydroxy groups. Song et al. synthesized a series of octadecyl ammonium bromides with none, one, two, and three hydroxyethyl groups [57] 9-12 (Figure 3). The $\mathrm{d}$ spacings of the lamellae in the crystal state, decrease by increasing the number of hydroxyethyl groups $\left(\mathrm{d}_{0-\mathrm{OH}}=30.7 \AA, \mathrm{d}_{1-\mathrm{OH}}=27.0 \AA, \mathrm{d}_{2-\mathrm{OH}}=26.9 \AA, \mathrm{d}_{3-\mathrm{OH}}=24.3 \AA\right)$ as was the case for the methyl ammonium analogs and are rationally close to their respective values $\left(\mathrm{d}_{2-\mathrm{OH}}=24.5\right.$ for the methyl octadecyl dihydroxy ethyl ammonium bromide). This means a larger tilt angle of the octadecyl chains with respect to the normal layer and larger available surface areas for a potential tetragonal arrangement. By comparing lamellar periods with the respective alkyl dihydroxy methyl counterparts and taking into account Tanford's [58] equation for the length of alkyl chains in the solid-state and a fully extended zigzag conformation $d(\AA)=1.5+1.265 n_{c}$, where $n_{c}$ is the number of the carbon atoms, the authors realistically estimate the layer thickness in the orthogonal arrangement to $32.8 \AA$ and the tilt angles $20.6^{\circ}, 34.6^{\circ}, 34.9^{\circ}, 42.2^{\circ}$. After the first thermal transition, the hydroxyethyl and dihydroxy ethyl derivative formed smectic $\mathrm{T}$ phases with lattice parameter $a=6.94 \AA$ the same as that of the methyl counterpart ( $6.95 \AA)$. Thus, the slightly bigger cation affects neither its tetragonal conformation nor its dimensions. The increase in the size of the polar head though favors substantially the formation of smectic $\mathrm{T}$ phases since the dimethyl octadecyl hydroxyethyl ammonium bromide does not exhibit mesophases at 
all [59]. The authors attribute this "beneficial" effect to weakened electrostatic attractions between quaternary ammonium cations and bromine anions.

A more recent effort to approximate the ideal conditions for achieving tetragonal symmetry was performed by the synthesis of $\mathrm{N}$-alkyl-N-carboxydecyl-N, $\mathrm{N}$-dimethyl ammonium bromides 7 (Figure 3) [60], so as to take advantage of the carboxylic acid dimerization at the terminus of a long aliphatic chain. In the solid-state, lamellar conformation was established by no less than 11 harmonics. The thickness of the carboxy decyl ammonium sublayer was estimated from the Y-intercept of the layer period d versus the number of carbon atoms of the long aliphatic chain. For the two crystal conformations $\mathrm{K}_{1}$ at room temperature $\mathrm{d}=21.24 \AA, \mathrm{K}_{2} 55-70{ }^{\circ} \mathrm{C}, \mathrm{d}=18.07 \AA$ ). A comparison of these two sublayers with those of the shorter carboxy alkyl quaternary ammonium counterparts (methyl and pentyl) permitted to establish a linear correlation of the sublayer thickness to the number of carbon atoms of the spacer (secondary shorter alkyl chain) as well. Additionally, from the respective Y-intercepts, the length of a carboxy and a dimethyl ammonium group was estimated to be $6.74 \AA$. The tilt of the carbon chains was $33^{\circ}$ in $K_{1}$, a typical value for quaternary salts with hydroxy and carboxy-terminal groups, very close to the respective values of hydroxyethyl $\left(34.6^{\circ}\right)$ and dihydroxy ethyl $\left(34.9^{\circ}\right)$ derivatives and only $7^{\circ}$ in $K_{2}$ in single-layered conformation, since a double layout would require prohibitive tilts $\left(65^{\circ}, 58^{\circ}\right)$. Molecular areas $\left(\mathrm{S}_{\mathrm{K} 1}=46.7 \AA^{2}\right.$ and $\mathrm{S}_{\mathrm{K} 2}=40.6 \AA^{2}$ ) are suitable for both interdigitation of the aliphatic parts and a smectic $\mathrm{T}$ phase. In the mesophase, the $\mathrm{X}$-ray diffraction patterns contain up to eleven equidistant peaks for smectic lamellae of $d_{12}=40.34 \AA, d_{14}=42.77 \AA$, $\mathrm{d}_{16}=47.50 \AA, \mathrm{d}_{14}=50.00 \AA$. In the wide-angle, though the multiplicity of the peaks was far too large to fit a tetragonal symmetry and reminiscent to the smectic $\mathrm{H}$ phase described by at first by Levelut [61]. At first, the dimensions of the monoclinic lattices $\left(P 2_{1} / \alpha\right.$ or $P 2_{1}$ symmetry, 2 molecules per unit cell) for example these for the dodecyl compounds ( $a=9.91 \AA b=4.73 \AA c=40.34 \AA \beta=114.6^{\circ}$ ) seem completely irrelevant to the smectic phases of the hydroxy derivatives even if they correspond to similar surfaces $46.87 \AA^{2}$ to about $48 \AA^{2}$. A more careful view, however, will reveal that in the two-dimensional orthogonal lattice $a / 2=4.95$ close to $b$. Furthermore, $4.92 \times \sqrt{ } 2=6.98 \AA$. The distance thus between two positive nitrogen cations or two negative bromine anions along the a-axis is the same as in the smectic T mesophases of the hydroxy derivatives. Along the $b$ axis, the distance is slightly $(0.31 \AA)$ smaller $(6.67 \AA)$. The monoclinic lattice is therefore generated by a distortion (shortening of the $b$ dimension) of the tetragonal lattice and a $45^{\circ}$ rotation. It possesses, additionally, a translational symmetry of the ionic lattice in the third dimension at an angle $114.6^{\circ}-90^{\circ}=24.6^{\circ}$ (Figure $7 \mathrm{a}-\mathrm{f}$ ).

The three-dimensional sub-cell presented in the solid-state by quaternary ammoniums functionalized by cyano groups could be "locked" by the replacement of the dipolar interactions by covalent bonds. A first attempt was performed by Alami for a series of alkanediyl- $\alpha, \omega$-bis(dimethyl alkyl ammonium bromides) 13 (Figure 8) [62]. No thermotropic mesophases were detected. In contrast, Fuller reported diffraction data for the smectic organization of dipentadecyl gemini diammonium surfactants 14 [63]. The values for $\mathrm{m}=1$ match perfectly with the $(1,1),(2,1)(3,0)$, and $(4,0)$ theoretical reflections for a square lattice of about $6.41 \AA$, while there is a deviation for $(2,0)$ of about $0.2 \AA$, indicating the possible existence of 3D symmetry. Reflections corresponding to this unit cell have also been detected for the $\mathrm{m}=3(3,0)$ and $(4,0)$ and $\mathrm{m}=5(1,1)$ derivatives.

In a second effort to stabilize the long-range tetragonal positional order, a series of compounds with two, three, and four dimethyl quaternary ammonium bromide polar heads interconnected by ethylene spacers and bearing dodecyl aliphatic chains were synthesized [64]. The X-ray powder diffraction pattern of the tetramer $\mathbf{1 5}$ (Figure 8) at room temperature contained four diffuse non-symmetrical peaks, indicating a semicrystalline state. Superimposed in the small angles' region were the equidistant peaks of the smectic arrangement $(\mathrm{d}=27.25 \AA)$. This lamellar period $\mathrm{T}$ is, surprisingly, slightly bigger than the respective value of the dodecyl cyanopropyl dimethyl ammonium bromide (25.9 $\mathrm{A})$, thereby implying an orthogonal configuration of the alkyl chains. In the wide angles area, 
the typical motif of the tetragonal symmetry is present with $\mathrm{a}=6.04$, the same as that reported by Alami for the first smectic $\mathrm{T}$ phase. This time though there is long-range positional 3D order and this organization is characterized as crystal smectic $\mathrm{T}$.

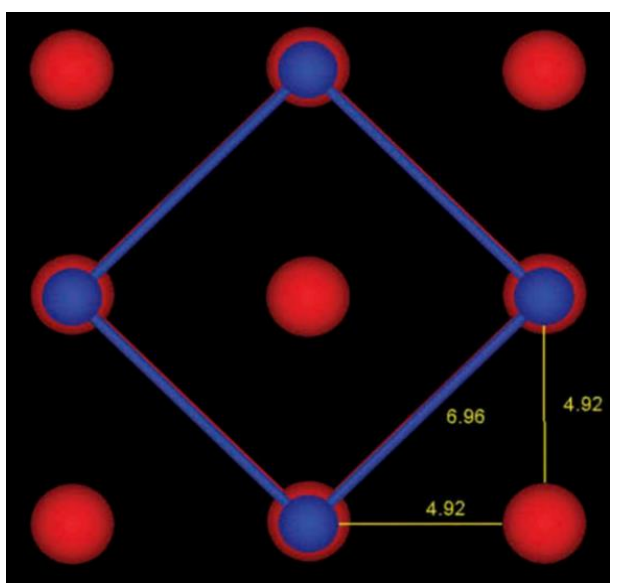

(a)

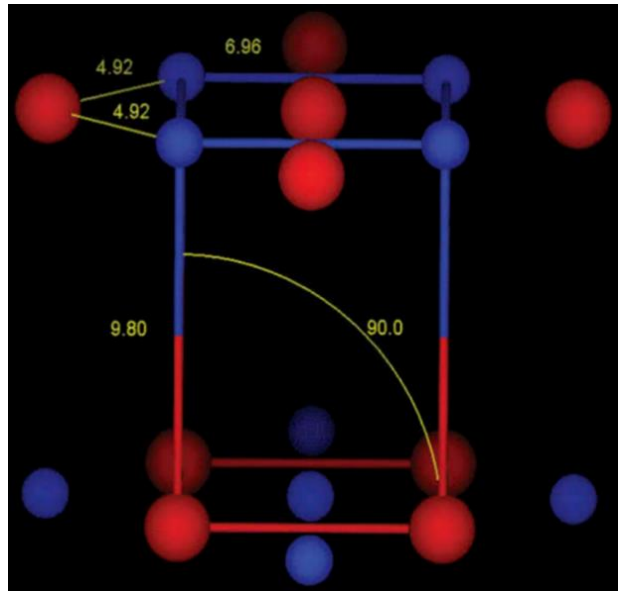

(c)

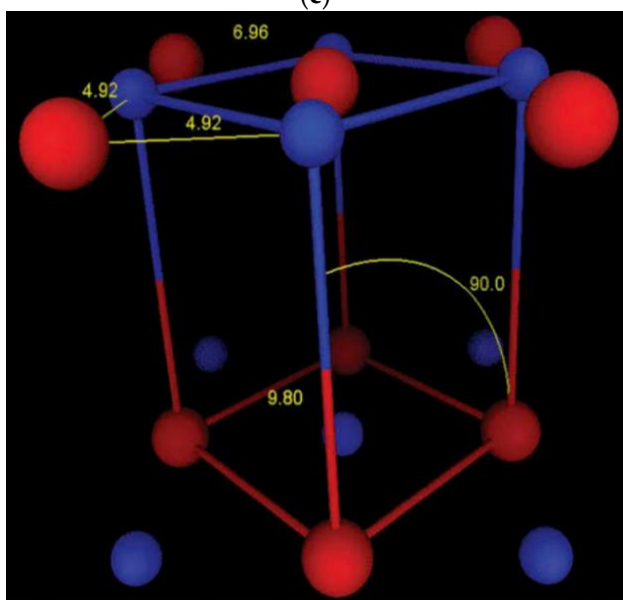

(e)

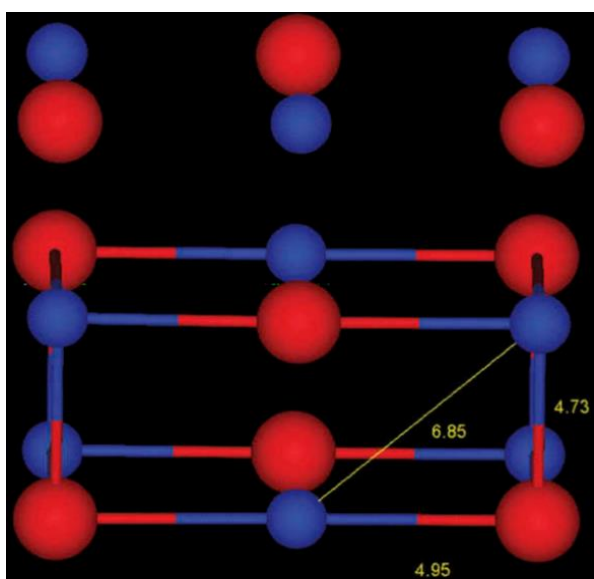

(b)

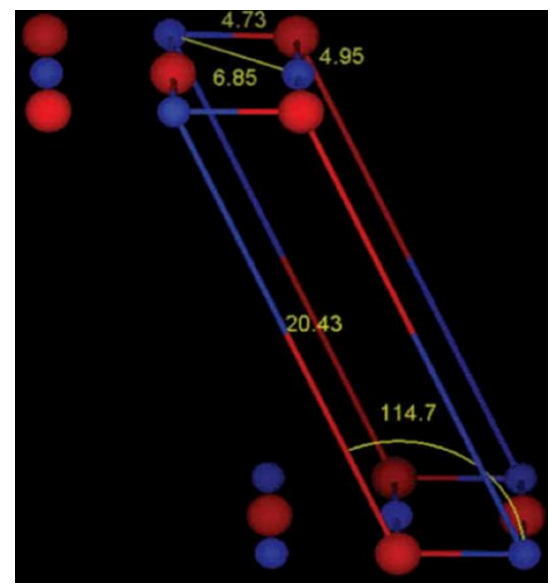

(d)

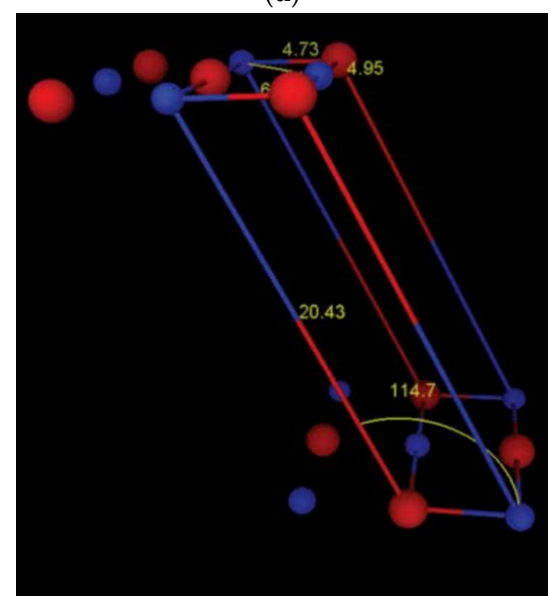

(f)

Figure 7. (a) Top view of the molecular arrangement of the orthogonal unit cell of the polar sublayers of the smectic T phase of N-alkyl-N, N-dihydroxy ethyl-N-methyl ammonium bromides (b) Top view of the monoclinic unit cell of the smectic $\mathrm{H}$ phase of $\mathrm{N}$-dodecyl-N-carboxydecyl-N, $\mathrm{N}$-dimethylammonium bromides. Bromine atoms are colored red and nitrogen atoms blue. (c,d) Respective side-views and $(\mathbf{e}, \mathbf{f})$ perspective views. All reproduced under permission from [60]. 


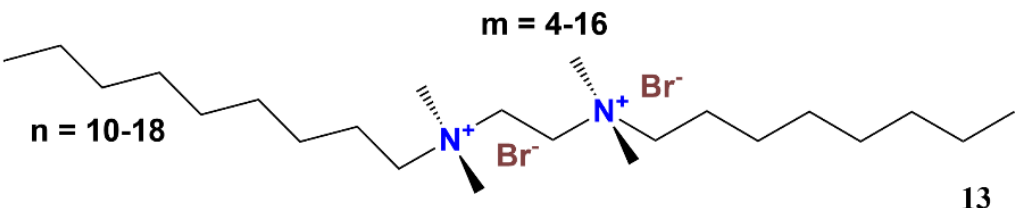

13
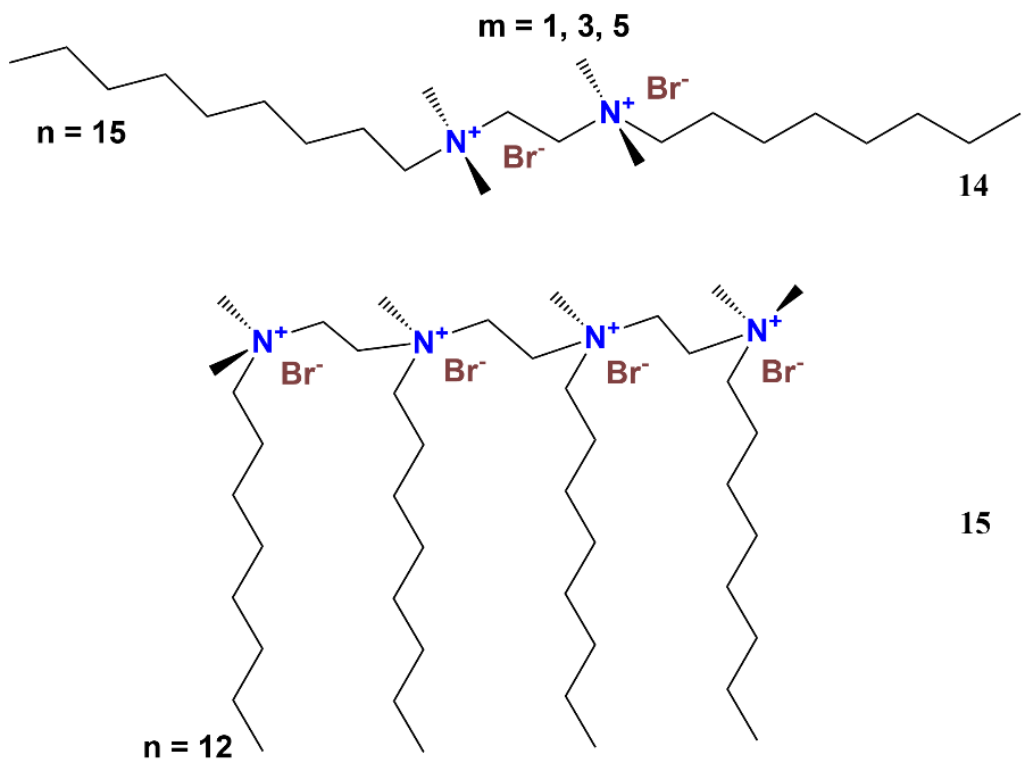

15

Figure 8. Chemical formulas of alkanediyl- $\alpha, \omega$-bis(dimethyl alkyl ammonium bromides) (13), pentadenanediyl- $\alpha, \omega$-bis(dimethyl alkyl ammonium bromides) (14), dimethyl dodecyl quaternary ammonium bromide tetramer (15).

A different approach followed by Tittarelli from the same group as Alami was to functionalize the one aliphatic chain with a calamitic end 16 (Figure 9) [65]. Even though these two species have different in-layer packing symmetries and cross-sectional areas, the structural compatibility between flexible aliphatic and rigid oxy nitro stilbene sublayers was observed. The two reflections in the wide-angle region indicate a tetragonal symmetry for all $(\mathrm{n}, \mathrm{m})$ combinations tested with a slightly different lattice parameter $(6.15 \AA)$ than the original $\left(6.04 \AA^{2}\right)$ and molecular area $37.8 \AA^{2}$. Given the fact that in the small angles' region the intensity of the harmonic Bragg reflections oscillates, a bi-layered ionic network of ammonium and bromine ions was established (Figure 10). The distance between the two ionic planes, separated by the simple alkyl chains was easily estimated for the dodecyl derivatives from the linear variation of the smectic periods as a function of total carbon atoms $(\mathrm{n}+\mathrm{m}) c=18.1 \AA$. It is impressive that, in this instance, the calamitic molecules adapted their organization to preserve the tetragonal symmetry of the ionic sublattice. Concerning the calamitic moieties, their cross-sectional area was only $22 \AA^{2}$, excluding orthogonal conformation. Single layers led to a huge void 37.8-22 =16 $\AA^{2}$. Double layers do not fit (they are short of $6 \AA^{2}$ ). They have to be tilted away from the layer normal by an angle of $\cos ^{-1}(22 / 37.8)=54.5^{\circ}$ to adapt to the area of the ionic lattices. This angle is nearly identical to the angle (54.7 degrees) between the $\left(\begin{array}{llll}0 & 0 & 1\end{array}\right)$ cubic lattice axis and the $\left(\begin{array}{lll}1 & 1 & 1\end{array}\right)$ diagonals. Thus, although the symmetry of their projection to the ionic plane is tetragonal, the rigid rods are laterally packed in hexagonal symmetry (Figure 11). 


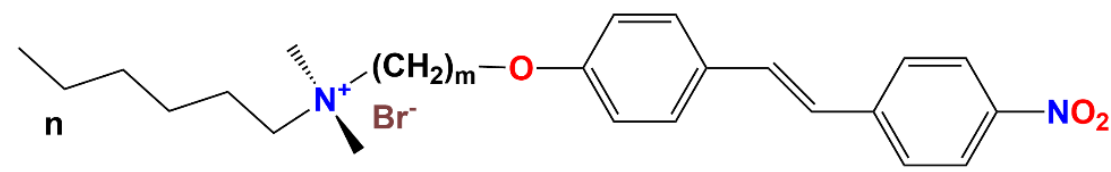<smiles>CCCCCCCCOc1cccc(OCCCCCCCC[N+](C)(C)Br)c1</smiles>

Figure 9. Chemical formulas of oxy nitro stilbene derivatives of dialkyl dimethylammonium bromides (16), N,N,N- trimethyl-8-[3-(octyloxy)phenoxy]octan-1-ammonium bromide (17).

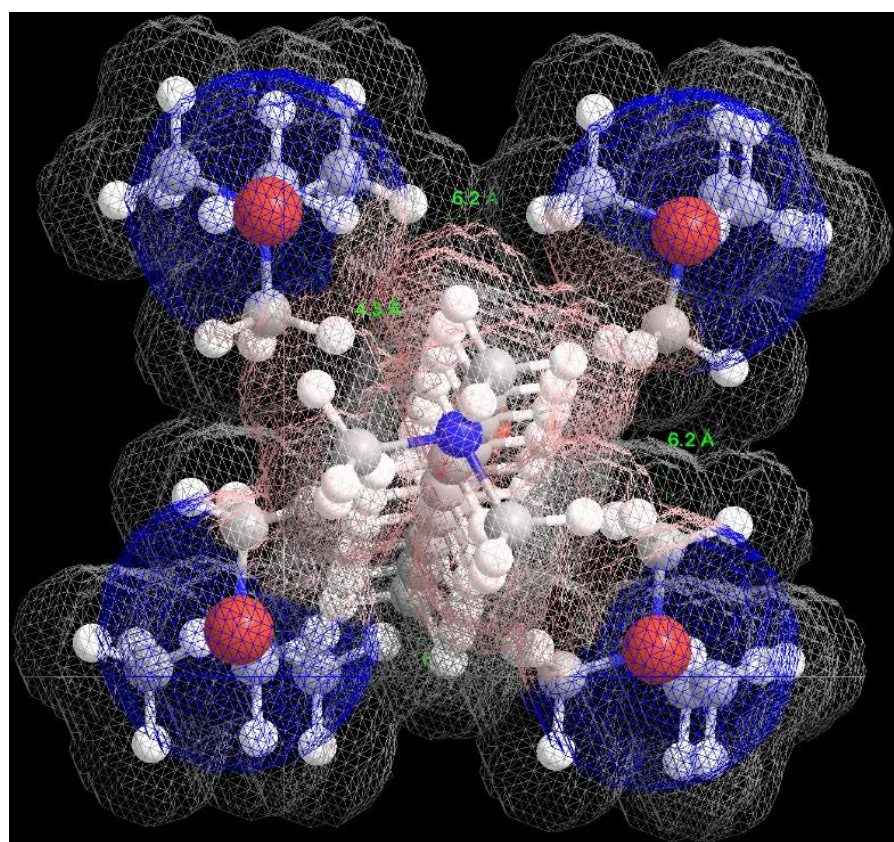

(a)

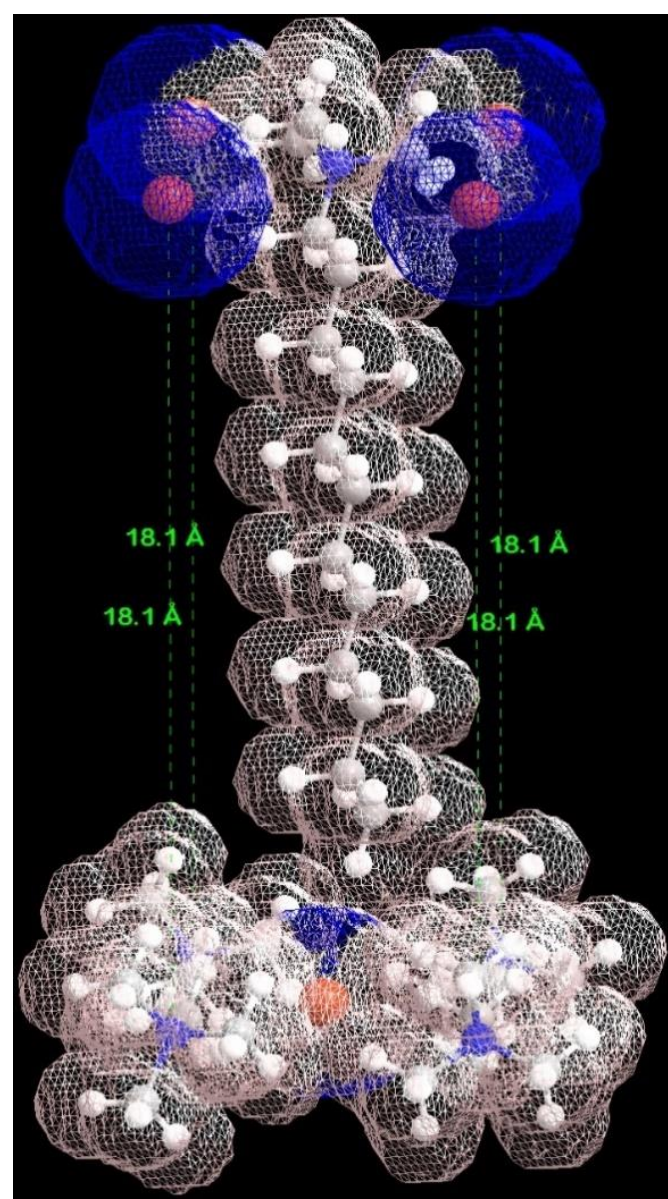

(b)

Figure 10. Top (a) and side (b) views of the organization and positive (red) and negative (blue) charge distribution of the tetragonal polar sublattice of oxy nitro stilbene dialkyl dimethylammonium bromides.

Modification of the aliphatic chains was also performed by the insertion of a phenylenedioxy group in the middle of the alkyl chain transforming simple trimethyl hexadecyl ammonium bromide to N, N, N- trimethyl-8-[3-(octyloxy)phenoxy]octan-1-aminium bromide 17 (Figure 9) [66]. This intervention drastically changed the thermal behavior and instead of a solid-solid transition at $103{ }^{\circ} \mathrm{C}$ [67], a solid to smectic T emerged at $74.3^{\circ} \mathrm{C}$. Impressively, a perturbation of the hydrophobic interactions generates not only liquid crystallinity but also the highly ordered and symmetric smectic $\mathrm{T}$ phase. The lattice parameter is $6.51 \AA$, corresponding to a molecular surface of $42.38 \mathrm{~A}^{2}$. This means that ammonium 
and bromide ions are not at the same level and there are most probably two molecules per tetragonal unit cell and interdigitation of the long hybrid chains.

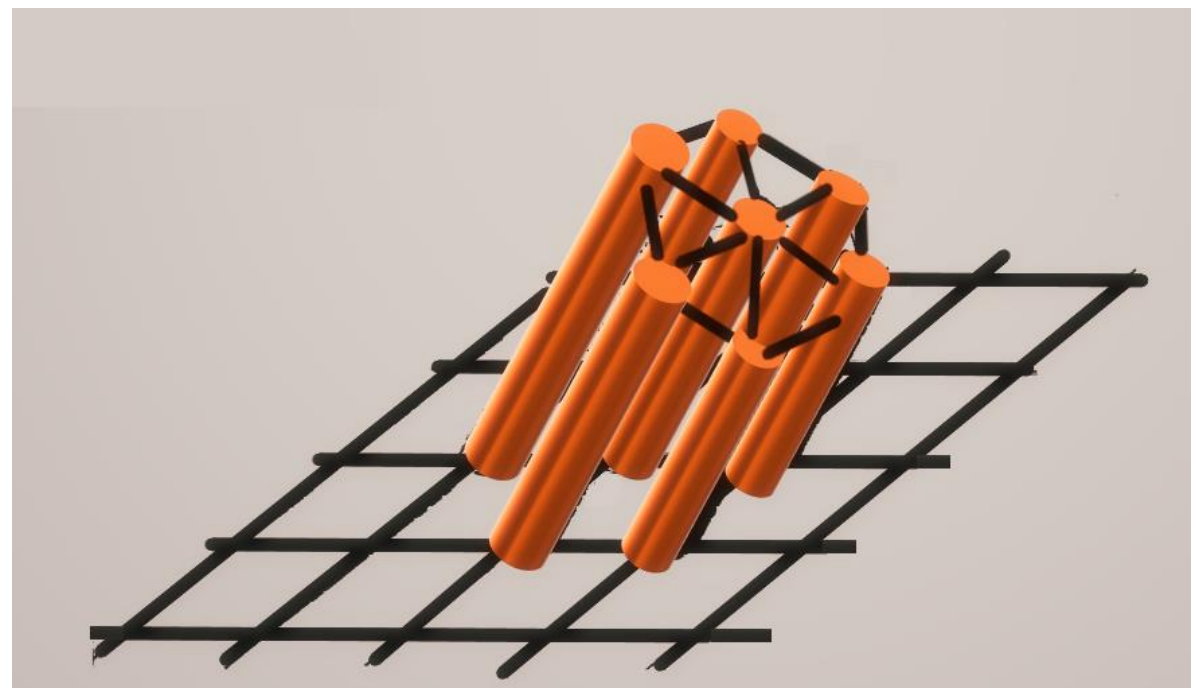

Figure 11. Rods placed at the nodes of a two-dimensional square network. When upright, the rods are laterally packed in a tetragonal fashion. When leaning over the diagonals of the square network, they are packed according to a centered rectangular two-dimensional lattice. When their tilt concerning the plane normal is exactly 54.7 degrees, that is when the rods lie along the body diagonals of the cubic lattice erected from the square network, then the rods are arranged laterally in a hexagonal fashion Reconstructed under permission from [65].

\section{Cyclic Diamine and Polyamines Salts}

A further immobilization of the ammonium bromide lattice was performed by the synthesis of 1,4-dialkyl-1,4-diazoniabicyclo[2.2.2] octane dibromides 18 (Figure 12). This was the first smectic T phase detected through X-ray diffraction eight years before Alami [68], but was identified 14 years after [69]. A typical smectic phase $T$ was established for the di-hexadecyl derivative with lattice parameter $a=6.22 \AA$, and two ionic $\mathrm{N}^{+}-\mathrm{Br}^{-}$planes and one molecule per unit cell. For the di-tetradecyl and di-dodecyl counterparts, the (111) reflections of a 3D tetragonal lattice were additionally detected.

Analogous results are produced with simple monocyclic aliphatic diamino compounds too with different alkyl sulfate counterions. Besides the size of sulfate ions, 1,4-piperazinium di-n-alkyl sulfates [70] 19 (Figure 12) $(n=10,12,14,16,18)$ are structurally quite similar to diazoniabicyclo[2.2.2] octane dibromides. As expected in their solid phases they are organized in lamellae as well. The variation of the lamellar periods provides the thickness of the polar sublayers (7.4 $\AA$ ) which is suitable for the dimensions of the piperazinium ring in the chair conformation $(5.6 \AA)$ and the sulfate anion $(5 \AA)$. The aliphatic chains are tilted $17^{\circ}$, suggesting molecular areas of $39.97 \AA^{2}$. The diffraction pattern (Figure 13) of the mesophase after the first thermal transition corresponds to a rectangular P2mg plane group $\left(a=13.03 \AA b=5.83 \AA\right.$ ) with a surface of $75.96 \AA^{2}$ (Figure 14a) about twice the size of the calculated molecular area of the solid phase. The diffraction pattern of the decyl derivative displays additional reflections corresponding to a 3D monoclinic lattice $\left(a=13.09, b=5.85 \AA, c=23.54 \AA, \beta=98.9^{\circ}\right)$. This intermediate phase is observed in a rather small temperature range before a second transition to a $2 \mathrm{D}$ smectic T phase (3D for the decyl derivative) with $a=6.15 \AA$ and surface area $37.82 \AA^{2}$, almost exactly half of the rectangular face (Figure 14b). The width of the polar sublayers in both phases is identical to that of the solid-state $\left(7.4 \AA\right.$ ) and both calculated molecular areas equal $35.4 \AA^{2}$. Therefore, each rectangular lattice contains two piperazine moieties in alteration with the sulfate anions in a probable herringbone arrangement (Figure 14c,e). The tetragonal analog was most probably generated by the destruction of this conformation by the thermal rotation of the piperazine 
rings (Figure 14d,f). The replacement of 1,4-piperazinium ring by 1,5-homopiperazinium 20 (Figure 12) reduces the symmetry and produces larger polar sublayers (8.4 $\AA$ ) partly due to the size of the cyclic diamine, a $29^{\circ}$ tilt of the aliphatic chains in the solid-state and molecular areas of $45 \AA^{2}$. The differentiations are not dramatic and, as previously observed for the dihydroxy quaternary ammonium derivatives, they are not prohibitive for the formation of Smectic T phases. Yet, in this instance, the organization of the ions in the solid-state does not survive the temperature increase and only smectic A phases are observed. At this point, it is interesting to note that alkyl sulfates of larger cyclic triamine $\mathbf{2 1}$ and tetraamine $\mathbf{2 2}$ multications display about the same polar layer thickness $(7.9$ and $8.5 \AA)$. The tetra azo derivatives form a slightly inclined monoclinic smectic phase $\beta=88^{\circ}$ ) very close to a rectangular lattice that twice as big as that discussed above, and does not transform to the smectic T phase [71]. Moreover, quaternary tetradecyl piperazinium salts with bromide, dodecyl sulfate, and a variety of other anions (tetrafluoroborate, hexafluorophosphate, dihexylsulfosuccinate, bis(trifluoromethylsulfonyl)imide, di-cyclohexyl sulfosuccinate, and dioctyl sulfosuccinate either form disorganized smectic A phases or do not form mesophases at all [72].

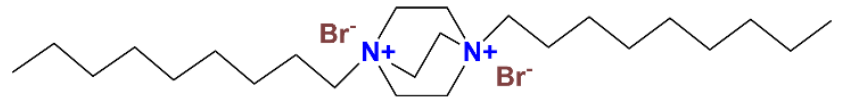

$\mathrm{n}=12,14,16,18$

18

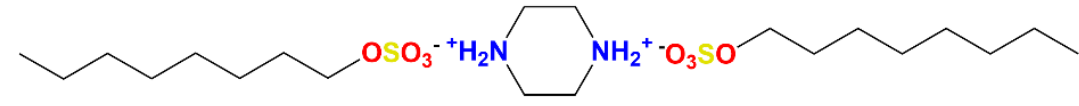

$n=10,12,14,16$

19

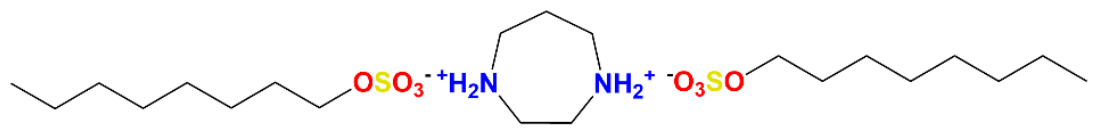

$n=10,12,14,16$

20

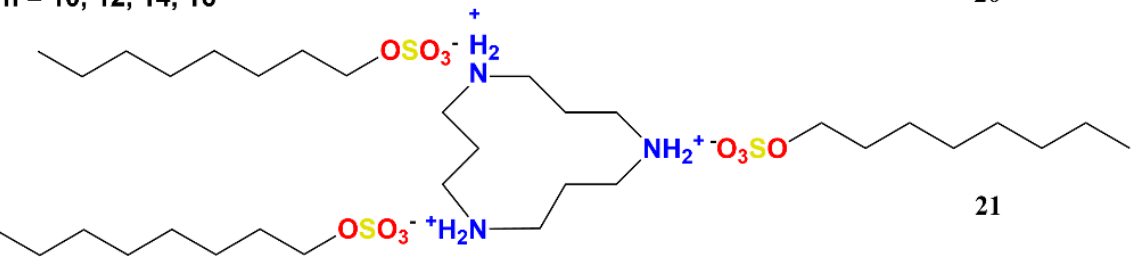

$\mathrm{n}=10,12,14,16$

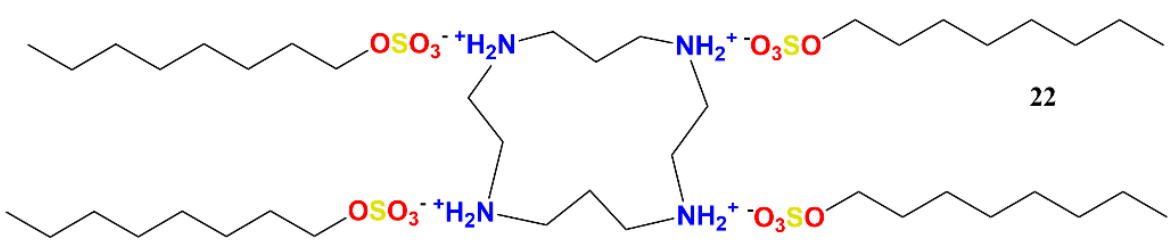

$n=10,12,14,16$

Figure 12. Chemical formulas of 1,4-dialkyl-1,4-diazoniabicyclo[2.2.2]octane dibromides (18), 1,4piperazinium di-n-alkyl sulfates (19), 1,5-homopiperazinium di-n-alkyl sulfates (20), trialkyl sulfates of triaza-cyclic triamine (21), tetralkyl sulfates of tetraza-cyclic triamine (22). 


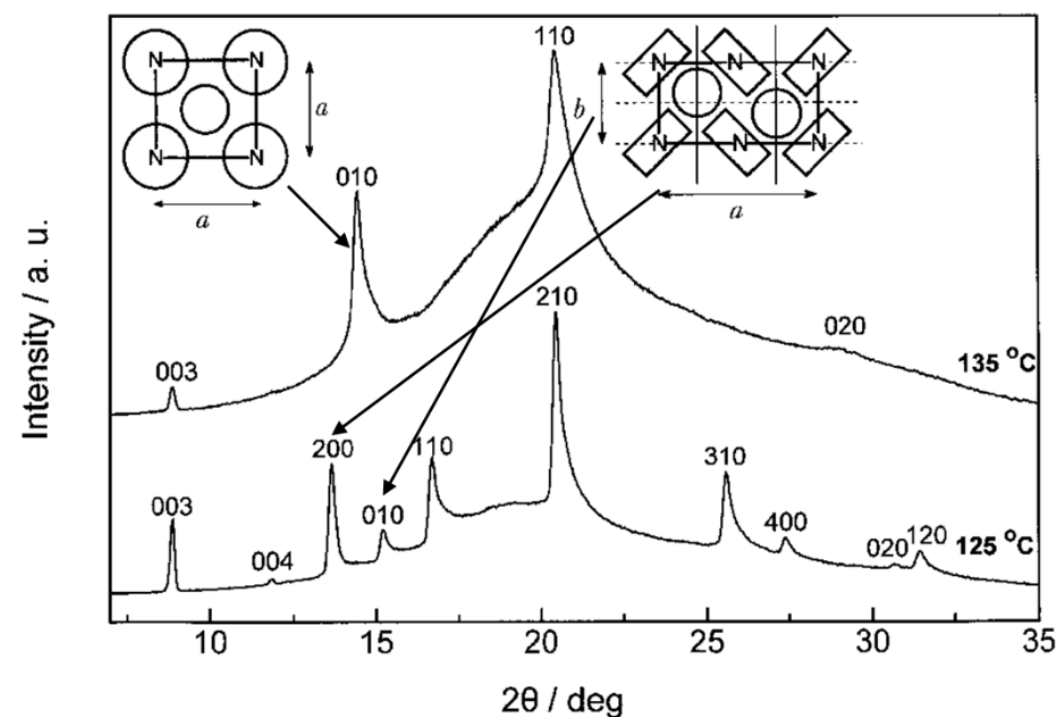

Figure 13. X-ray diffraction patterns of 1,4-piperazinium di-n-tetradecyl sulfate in the rectangular $\mathrm{S}_{\mathrm{E}}$ at $125^{\circ} \mathrm{C}$ and in the square $\mathrm{S}_{\mathrm{T}}$ phase at $135^{\circ} \mathrm{C}$. Reproduced with permission from [70].

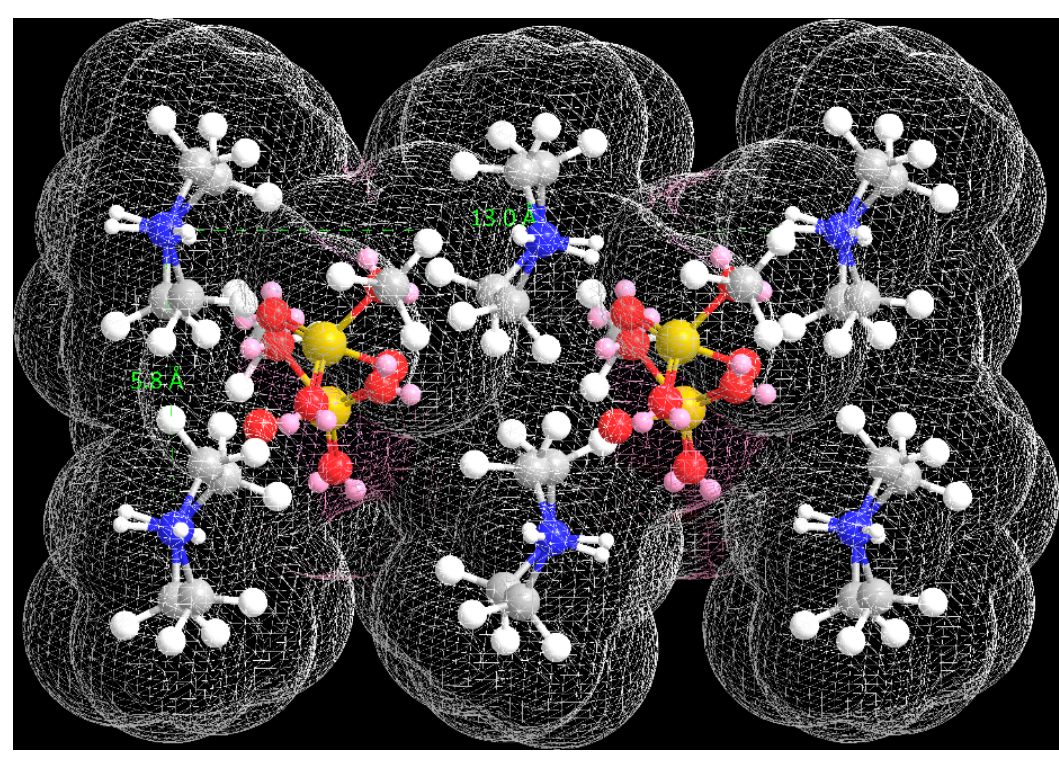

(a)

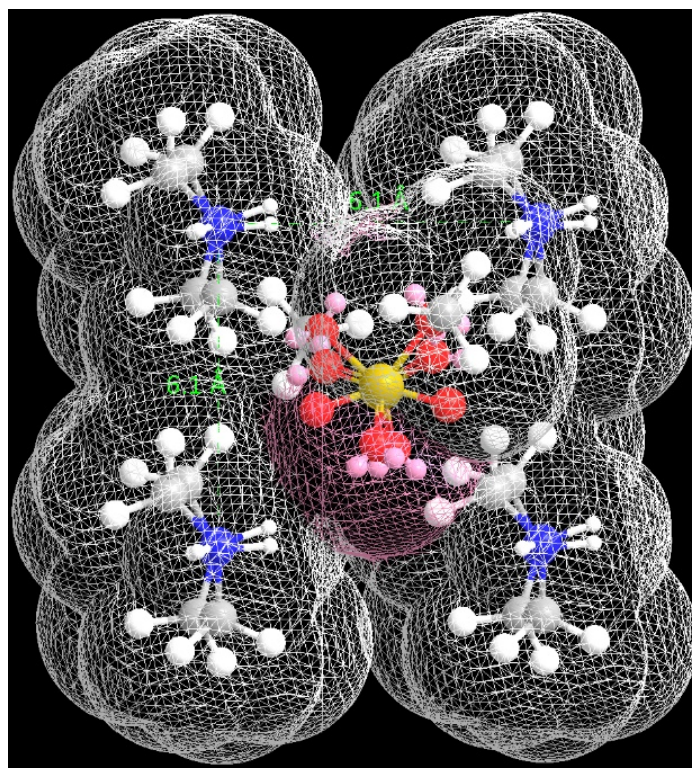

(b)

Figure 14. Cont. 


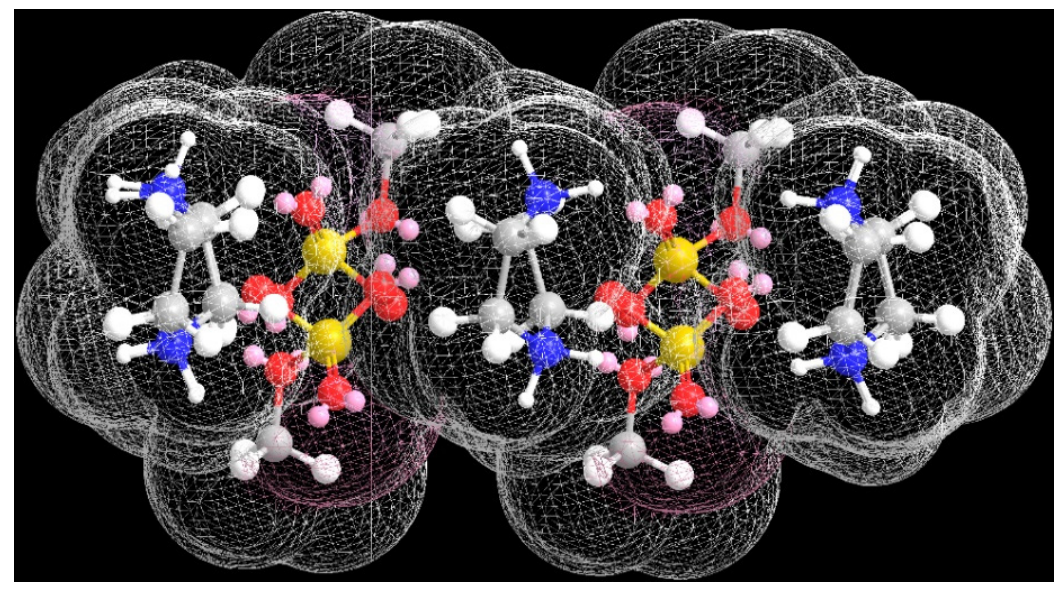

(c)

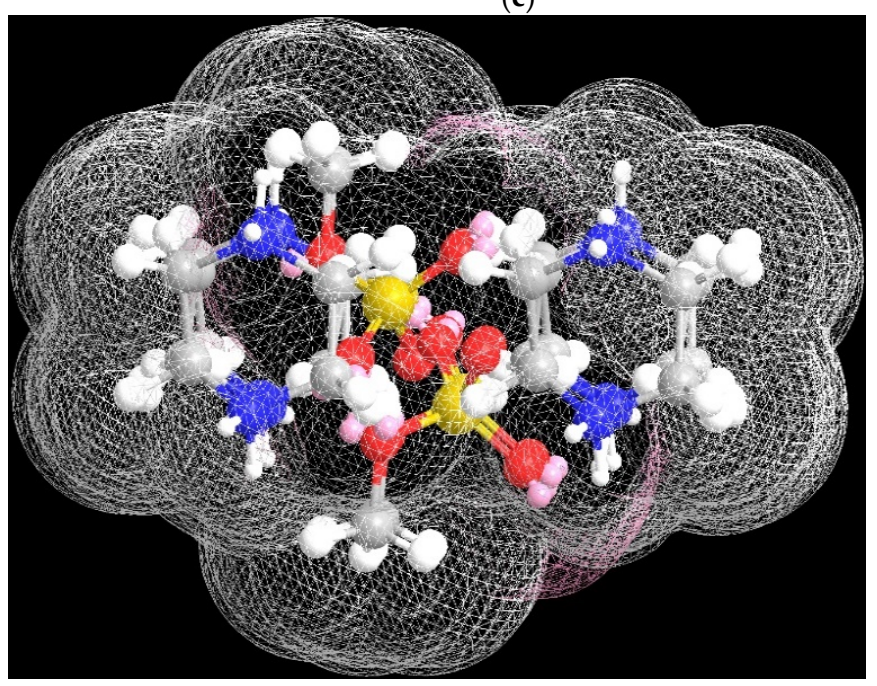

(e)

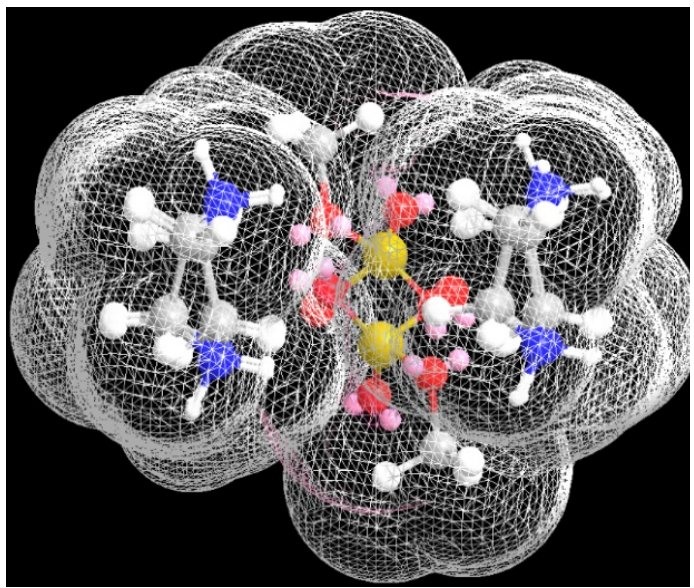

(d)

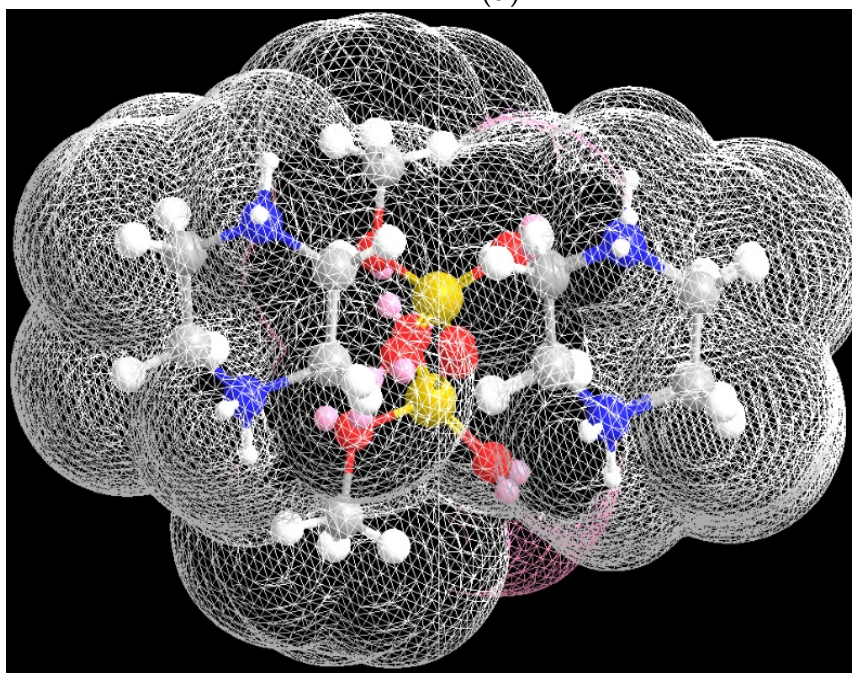

(f)

Figure 14. Top $(\mathbf{a}, \mathbf{b})$ side $(\mathbf{c}, \mathbf{d})$, and front views $(\mathbf{e}, \mathbf{f})$ of the organization of the rectangular $(\mathbf{a}, \mathbf{c}, \mathbf{e})$ and tetragonal $(\mathbf{b}, \mathbf{d}, \mathbf{f})$ polar sublattices of 1,4-piperazinium di-n-alkyl sulfates.

\section{Pyrrolidinium and Piperidinium Salts}

Another nitrogen cation compatible with the ionic liquid crystalline character and specifically smectic T mesophases is quaternary pyrrolidinium, since its synthesis from $\mathrm{N}$ alkyl pyrrolidine is similar to that of conventional quaternary ammonium salts. Goossens et al. performed a detailed study to achieve further insight into the nature of tetragonal mesogen arrangement and factors that favor it. N-alkyl-N-methylpyrrolidinium salts with different chain lengths 8 to 20 carbon atoms and different anions (bromide, tetrafluoroborate, thiocyanate, tetrabromouranyl, bis(trifluoromethylsulfonyl)imide, hexafluorophosphate, and tetrakis(2-thenoyltrifluoroacetonato) europate(III)) were initially researched (Figure 15) [73]. The first square liquid crystalline phases were observed for the undecyl pyrrolidinium bromides. Interestingly, for most compounds, two tetragonal phases (either enantiotropic for shorter chains or monotropic) were observed, termed crystal smectic $T_{1}$ and $T_{2}$. This is the first and to our knowledge, only example of molecules exhibiting two different tetragonal mesophases. The compounds with the tetrafluoroborate and the hexafluorophosphate counterions also exhibited crystal smectic $\mathrm{T}$ phases in contrast to thiocyanate, tetrabromouranyl, bis(trifluoromethylsulfonyl)imide, tetrakis(2thenoyltrifluoroacetonato)europate(III), and fluorohydrogenate [74]. In all cases, polar ionic lattices are arranged in double layers. The calculated distance is $9.9 \AA$ (Figure 16a) more than enough to accommodate two pyrrolidinium cations (Figure 16b) and surprisingly larger than that of bigger ion pairs such as piperazinium sulfates. The lattice parameters of 
$\mathrm{T}_{2}$ are about 6.3-6.4 $\AA$ corresponding to a surface of $40.6 \AA^{2}$. Respective values for $\mathrm{T}_{1}$ are slightly smaller $(6.28 \AA)$. Larger anions produce, as expected, larger squares $\left(\mathrm{BF}_{4}{ }^{-} 6.9 \AA\right.$, $\mathrm{PF}_{6}-7.29 \AA$ A). All lattices host two molecules per unit cell. The coupling of pyrrolidinium heads with rigid rod mesogens via flexible alkyl spacers of variable length did not produce smectic $\mathrm{T}$ phases [75].<smiles>[Y20][N+]1(C)CCCC1</smiles>

$$
\mathrm{n}=11-20
$$

$\mathrm{X}=\mathrm{Br}^{-}, \mathrm{B}_{4}^{-}, \mathrm{PF}_{6}^{-} 23$

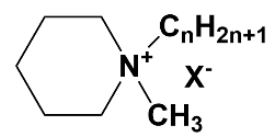

$n=14,16,18$ $\mathrm{X}=\mathrm{Br}^{-}, \mathrm{B}_{4}^{-}$,
24<smiles>CCCCCCCCCCCCO[Se]O[Na]</smiles>

Figure 15. Chemical formulas of N-alkyl-N-methyl pyrrolidinium salts (23), N-alkyl-N-methyl piperidinium salts (24), N-alkyl-N-methyl piperidinium alkyl sulfates (25).

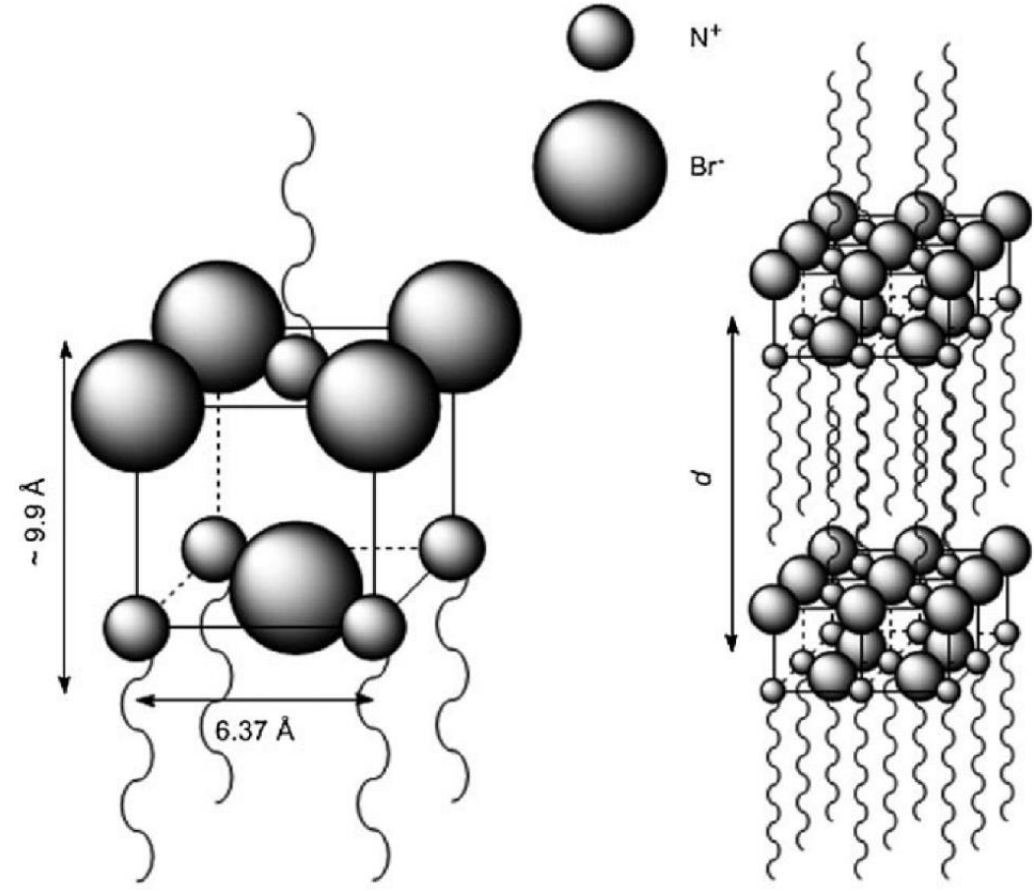

(a)
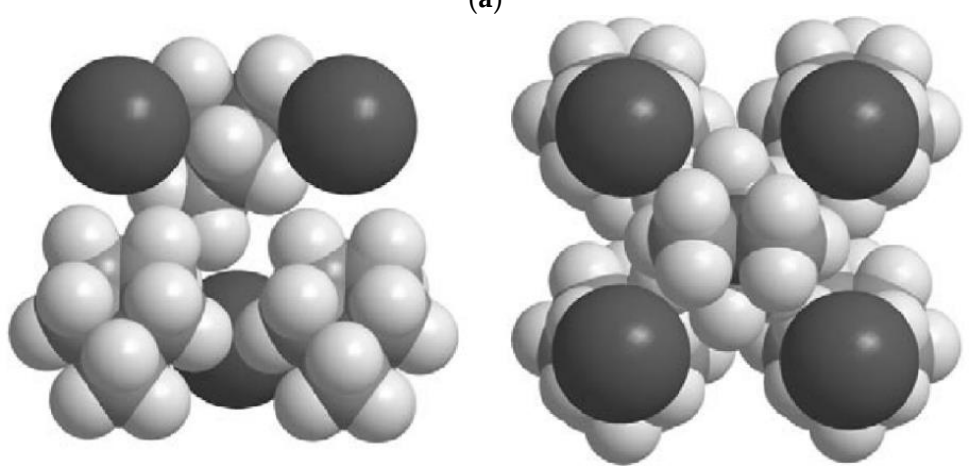

(b)

Figure 16. (a) Structural models for the $\mathrm{T}$ phases exhibited by pyrrolidinium salts. Left: unit cell of the 
tetragonal lattice (the carbon and hydrogen atoms of the pyrrolidinium ring and the methyl group on the nitrogen atom of the pyrrolidinium ring are omitted for clarity). Right: two ionic sublayers separated by the aliphatic continuum; $d$ is the layer thickness of the T layers (the length of the alkyl chains is underestimated for clarity); (b) Molecular packing in the T phases, as obtained by elementary molecular modeling (Chem3D software). Left: side view of a unit cell of the tetragonal lattice. Right: top view of a unit cell of the tetragonal lattice. For clarity, the long alkyl chains on the cations are replaced by single methyl groups. Before modeling, the structure of a pyrrolidinium cation was energy-minimized by an MM2 calculation within Chem3D. The pyrrolidinium ring is nonplanar, with the nitrogen atom sitting above the plane of the four-ring carbon atoms. Both reproduced with permission from [73].

Adding a sixth member to the pyrrolidinium ring forms the larger quaternary piperidinium cation 24 (Figure 15). Tetradecyl, hexadecyl and octadecyl bromides form crystal smectic T phases. The parameter of the square lattice $a=6.42 \AA$ corresponds to a surface area of $41.22 \AA^{2}$, which is about the same as the respective values of the pyrrolidinium counterpart. This phenomenon is equally observed in the tetragonal mesophases formed with the tetrafluoroborate counterion $a_{\text {pyrrolidium }}=6.9 \AA$ and $a_{\text {piperidinium }}=6.95 \AA$. In contrast, piperidinium does not form square mesophases with hexafluorophosphate, whereas it forms slightly larger square mesophases $(a=6.53 \AA$ ) with dodecyl sulfate [72] 25 (Figure 15) than the secondary piperazine analog $(a=6.15 \AA$ ).

\section{Aromatic Polar Heads}

The first examples of Aromatic Cations presenting tetragonal organization (dialkyl(1,4phenylene) diimidazolium salts with bis(trifluoromethane sulfonyl)imide anions $\mathbf{2 6}$ (Figure 17) have a dissimilar structure from the previously described compounds. The smectic $\mathrm{T}$ phase was reported mainly based on the polarizing optical microscopy's characteristic lancet-like texture and a peak at $2 \theta=17^{\circ}$ corresponding at a lattice parameter $7.4 \AA$ if it is the $\left(\begin{array}{lll}1 & 0 & 0\end{array}\right)$ reflection or $10.5 \AA$ if it is $\left(\begin{array}{lll}1 & 1 & 0\end{array}\right)$ [76]. The addition of one more aromatic core was performed to change the benzene core to naphthalene [77]. It has been observed in many cases that the latter tends to lower the transition temperatures to the mesophases [78]. Decyl and dihexadecyl (1,5-naphthalene) dimidazolium salts 27 (Figure 17) were synthesized with a variety of anions (Bromide, hexafluorophosphate, Triflate, Tetrafluoro Borate, and bis(trifluoromethane sulfonyl)imide. As was previously the case for the 1,4-phenylene derivatives, only bis(trifluoromethane sulfonyl)imide compounds displayed liquid crystalline phases and in fact with very similar diffraction patterns. The lattice parameter was calculated to $10.6 \AA$, which is almost the same as that hypothesized for the single phenyl ring confirming both the formerly suggested smectic $\mathrm{T}$ and the value for the lattice parameter. The most recent case of smectic $\mathrm{T}$ phase was detected for asymmetric alkyl hexyl 4,4'-bipyridinium salts, paired once more with the bistriflimide anion 28 (Figure 17) [79]. From the reported peaks ( $\left.\begin{array}{lll}1 & 1 & 0\end{array}\right) 7.3 \AA$ and $\left(\begin{array}{lll}2 & 0 & 0\end{array}\right) 5.2 \AA$, the lattice parameter is calculated as $\mathrm{a}=\mathrm{b}=10.4 \AA$ and is very close to that of the imidazolium salts. These dimensions correspond to a surface of $108.16 \AA^{2}$. Molecular modeling revealed that the optimal distance between the pyridinium cation and the imide anion is $5 \AA$, which is about half of the lattice parameter. Furthermore, because there is sufficient space for four aliphatic chains, a unit cell containing two molecules and interdigitated alkyl moieties is the most plausible hypothesis (Figure 18). This model excludes the self-rotation of the viologens around their axis. This requirement is highly probable since the positions of their pyridinium atoms are locked within the ionic frame. 

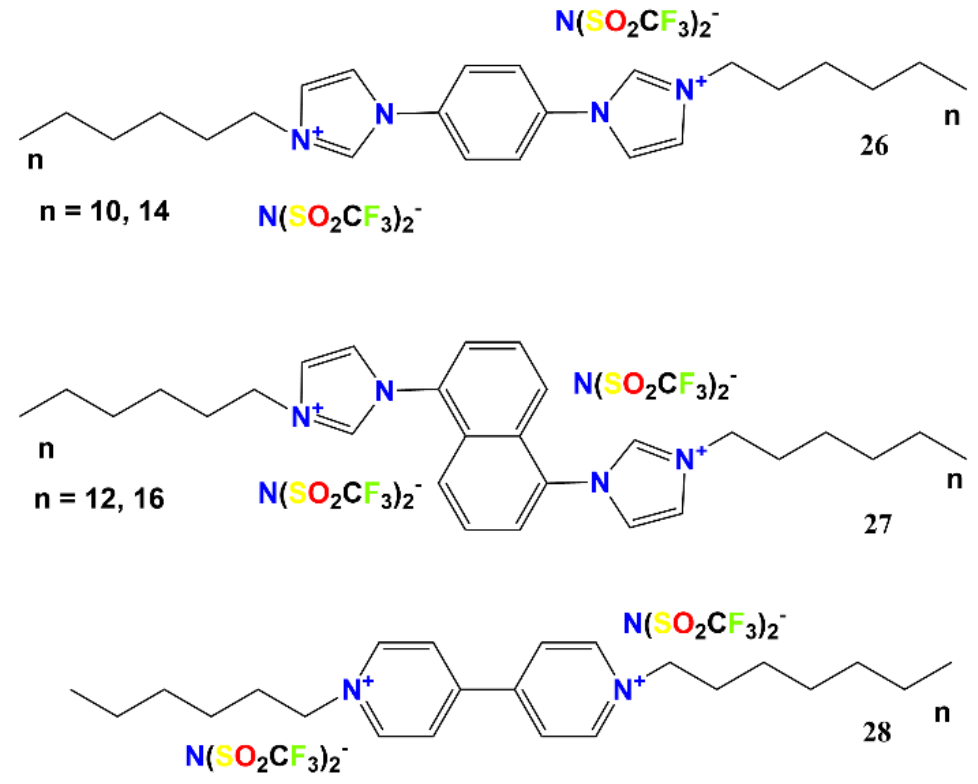

n $=5,7,10,11,12,14,16,18,20$

Figure 17. Chemical formulas of dialkyl(1,4-phenylene)diimidazolium bis(trifluoromethane sulfonyl)imides (26), dialkyl (1,5-naphthalene) diimidazolium bis(trifluoromethane sulfonyl)imides (27), alkyl hexyl 4,4'-bipyridinium bis(trifluoromethane sulfonyl)imides (28).

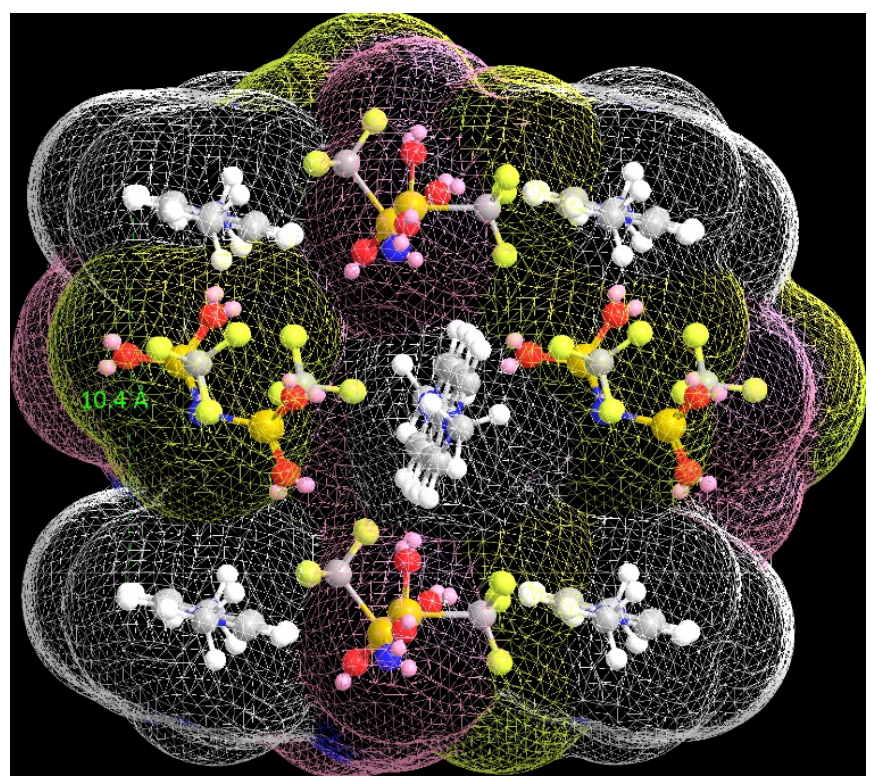

(a)

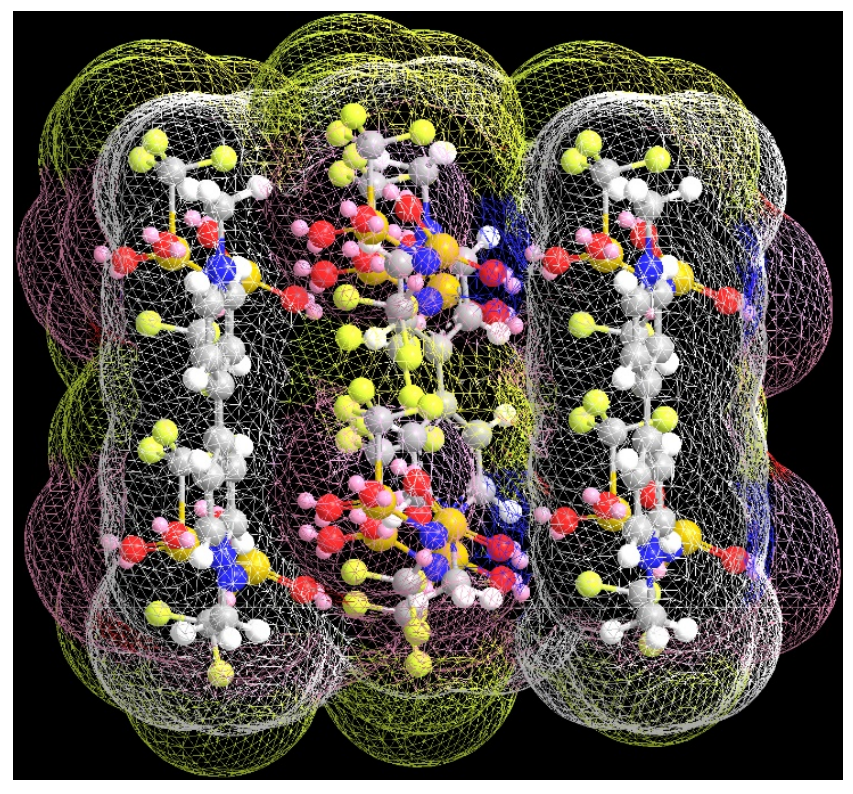

(b)

Figure 18. Top (a) and side (b) view of the organization of the tetragonal polar sublattice of the alkyl hexyl 4,4'-bipyridinium bistriflimides.

Bis-cationic gemini diimidazolium salts, bearing alkyl chains of variable length and separated by different spacers (hexane, diethyl ether, p-xylene, 2-butine) spacer (type D) were also tested as potential mesogens [80]. Even though none of the bromide salts exhibited a smectic $\mathrm{T}$ phase, Mudring and his group decided to additionally research a compound with ether bridges that presented the broader mesophase range bis(n-alkyl)-1,1(oxydi-2,1-ethane-diyl)bis-imidazolium with different anions. Both tetrahedral $\mathrm{BF}_{4}{ }^{-}$and $\mathrm{ClO}_{4}{ }^{-}$ions lowered the transition to mesophase temperatures and produced organization 
in squares. Octahedral and bulkier $\mathrm{PF}_{6}{ }^{-}$as well as di-bis(trifluoromethylsulfonyl)amide anion did not. This phenomenon is similar to the behaviour of pyrrolidinium and piperidinium salts, whereby $\mathrm{BF}_{4}{ }^{-}$was again proven the most convenient counterion to promote tetragonal symmetry. The reciprocal spacings of two sharp reflections in the small-angle were in the ratio $1, \sqrt{ } 2$. The smectic $T$ phase was suggested. The square lattice parameter for both anions is $33 \AA$ and close to the lamellar periods of the smectic A phases observed at higher temperatures. Since there were no equidistant peaks in the small-angle region this dimension fits rather to a columnar tetragonal configuration.

The last comment will be made on a recently reported highly ordered lamellar phase, possessing tetragonal symmetry that marginally fits the scope of this review, mostly because it is named crystal smectic $\mathrm{T}$ ' and for disambiguation purposes. It is a 'sandwich-like five layer' conformation observed at room temperature, comprising three different conformations of biphenyl phenyl esters modified by 3-alkyl imidazolium bromides [81]. One type of layer is formed by the coassembly of mesogens in two square conformations (Red, Green) (Figure 19) and the other is made exclusively by molecules adopting the third tetragonal ordering. The alternative stacking of these layers generates a 'sandwich-like five layer' (Figure 20) that is claimed as a new type of mesophase different from smectic T.

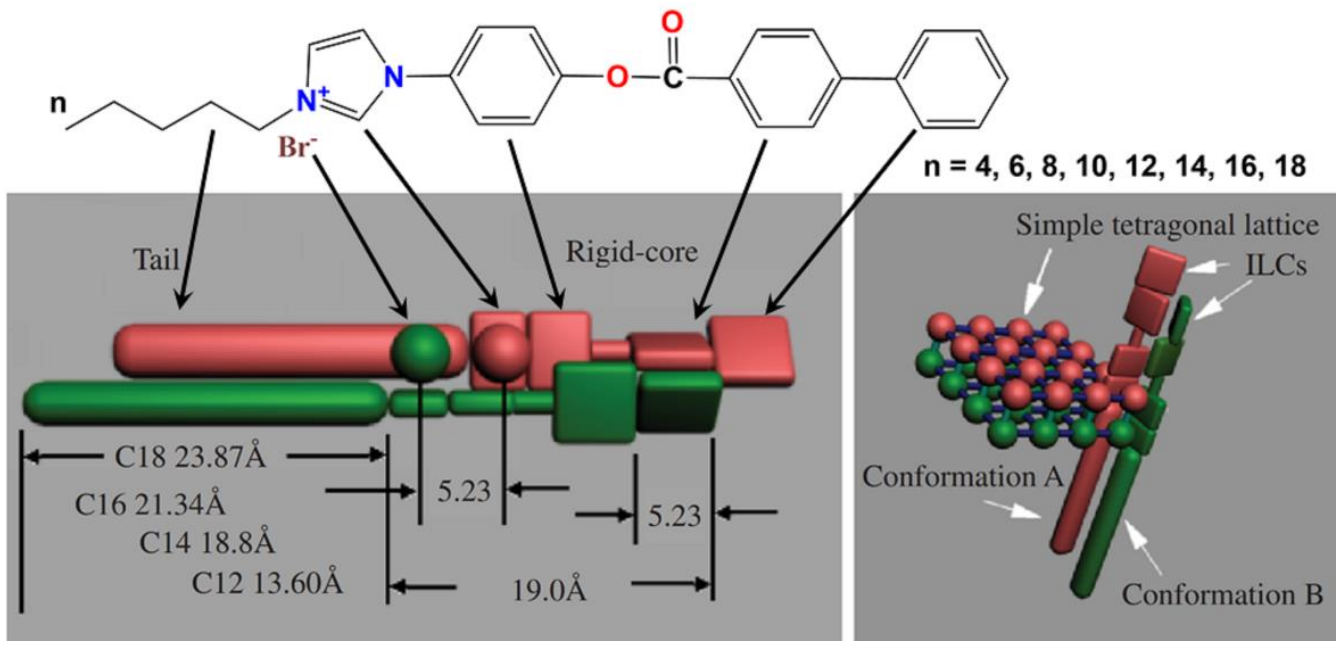

(a)

(b)

Figure 19. Molecular packing in 'ion-double layer': (a) Length of the fully extended mesogens and the aliphatic tails in an all-trans configuration, estimated by Chem3D, MM2 method; (b) Conformation A (red) and Conformation B (green) of the molecules and the simple tetragonal lattice of anions reproduced with permission from [79]. 

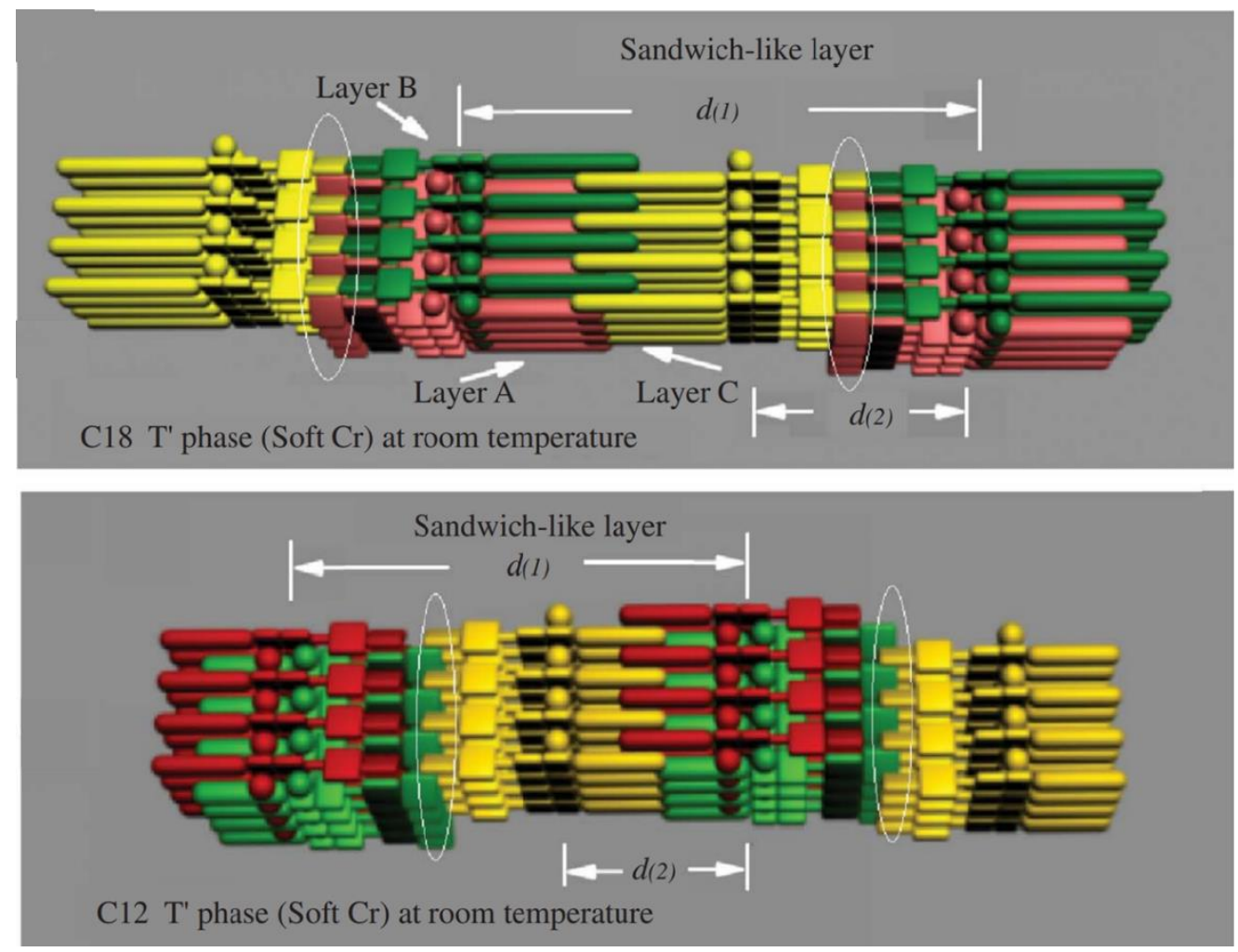

Figure 20. Schematic representation of the five-layered structures in the soft crystal phase for $\mathrm{C} 12$ and $\mathrm{C} 18$ by cooling to room temperature, simulated by 3D max. (up) $\mathrm{T}^{\prime}$ phase for C18 (down) tilted-T phase for $\mathrm{C} 12$ reproduced with permission from [81].

\section{Thermal Behavior}

This survey concludes with a summary of the thermotropic characteristics of the smectic T phase. Figures 21-24 depict the transition temperatures of the different types of compounds that form Smectic $\mathrm{T}$ phases along with some characteristic optical textures (mainly lancets). It is evident that in almost every case the thermal transition to the Sm T phase occurs below $100{ }^{\circ} \mathrm{C}$ with one interesting exception: the only secondary Nitrogen cation (piperazinium). Furthermore, the perturbation of the aliphatic chains leads to lower transition temperatures. The Smectic T phase is almost always the first liquid crystalline state emerging with the exception, again of the secondary piperazinium cation where it is preceded by the rectangular smectic E. It is a thermally stable mesophase resistant, in many instances, to temperatures above even $200^{\circ} \mathrm{C}$. When hydrogen bonding is involved between terminal hydroxy groups, it transforms to the Smectic A phase. Transition enthalpies to the Sm T phase are typical for a transition to a mesophase. In contrast, the respective enthalpies for isotropization are one order of magnitude higher than those of disordered phases possessing orientational order only, or positional order in one dimension [82]. 


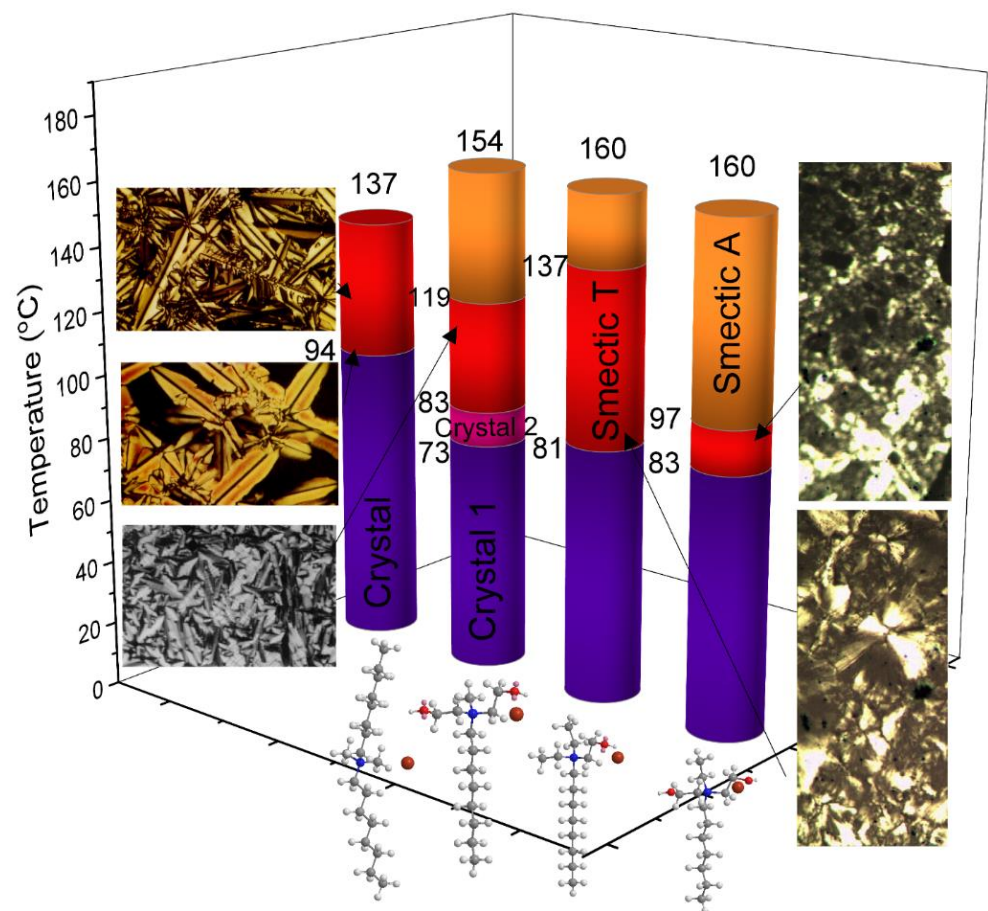

Figure 21. Thermal transitions and characteristic textures from left to right $\mathrm{N}, \mathrm{N}$-dimethyl, N, N, dioctadecyl) ammonium bromide; $\mathrm{N}, \mathrm{N}$ dihydroxy ethyl, $\mathrm{N}$, dimethyl, $\mathrm{N}$, octadecyl ammonium bromide; N, N diethyl, N, hydroxyethyl, N, octadecyl ammonium bromide; N, N, dihydroxy ethyl, $\mathrm{N}$, ethyl, $\mathrm{N}$, octadecyl ammonium bromide. Long aliphatic chains have been shortened for clarity. The textures are from $[50,55,57]$ and are reproduced with permission.

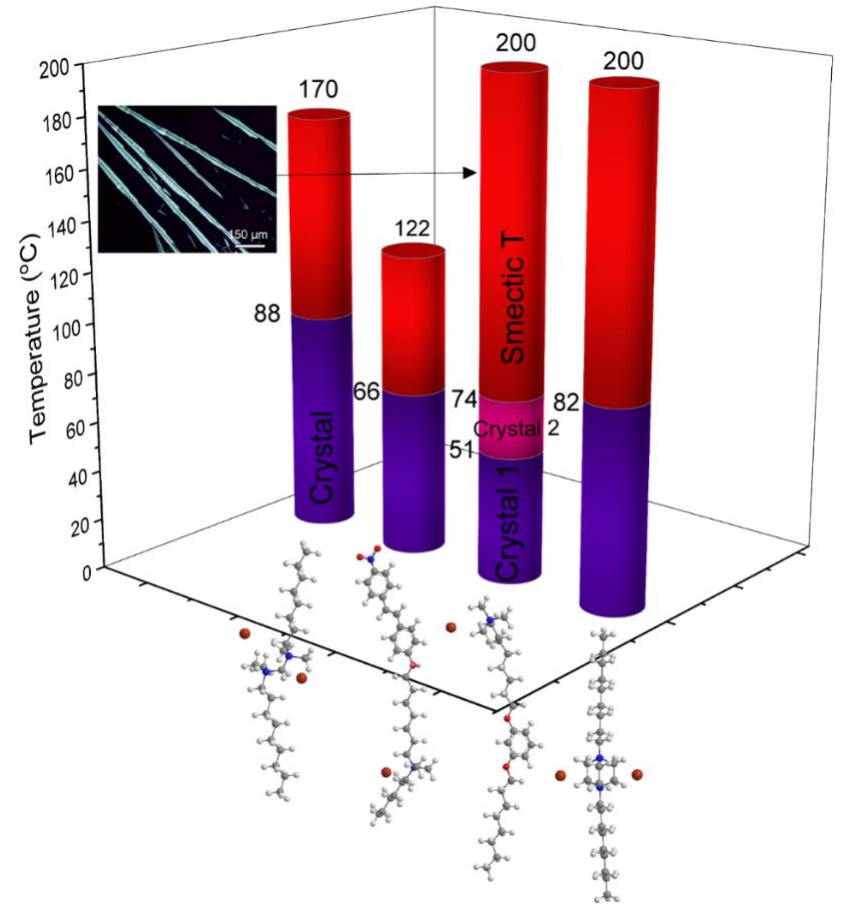

Figure 22. Thermal transitions from left to right $\mathrm{N}, \mathrm{N}, \mathrm{N}^{\prime}, \mathrm{N}^{\prime}$-tetramethyl-N, $\mathrm{N}^{\prime}$ dipentadecylmethanediammonium) bromide; dimethyl ( $\omega$-(4-((E)-2-(4-nitrophenyl)-1-ethenyl) phenoxy) octyl) dodecylammonium bromide, N,N,N-trimethyl-8-(3-(octyloxy)phenoxy) octan1-ammonium bromide together with a characteristic lancet texture and 1,4 didodecyl-1,4diazoniabicyclo[2.2.2] octane dibromide. Long aliphatic chains have been shortened for clarity. The texture is from [66] and is reproduced with permission. 


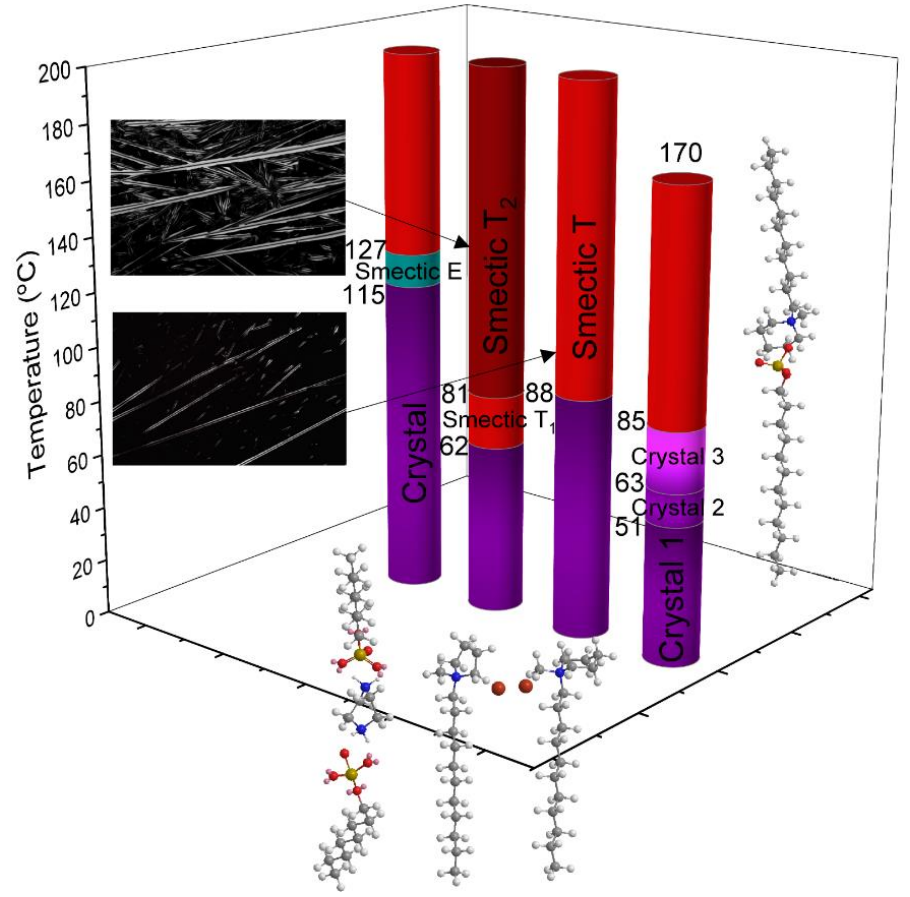

Figure 23. Thermal transitions and characteristic lancet textures from left to right 1,4 piperazinium ditetradecyl sulfate, 1-methyl-1-undecylpyrrolidin-1-ium bromide, 1-methyl-1-tetradecylpiperidin-1ium bromide, 1-methyl-1-tetradecylpiperidin-1-ium dodecyl sulfate. Long aliphatic chains have been shortened for clarity. The textures are from $[72,73]$ and are reproduced with permission.

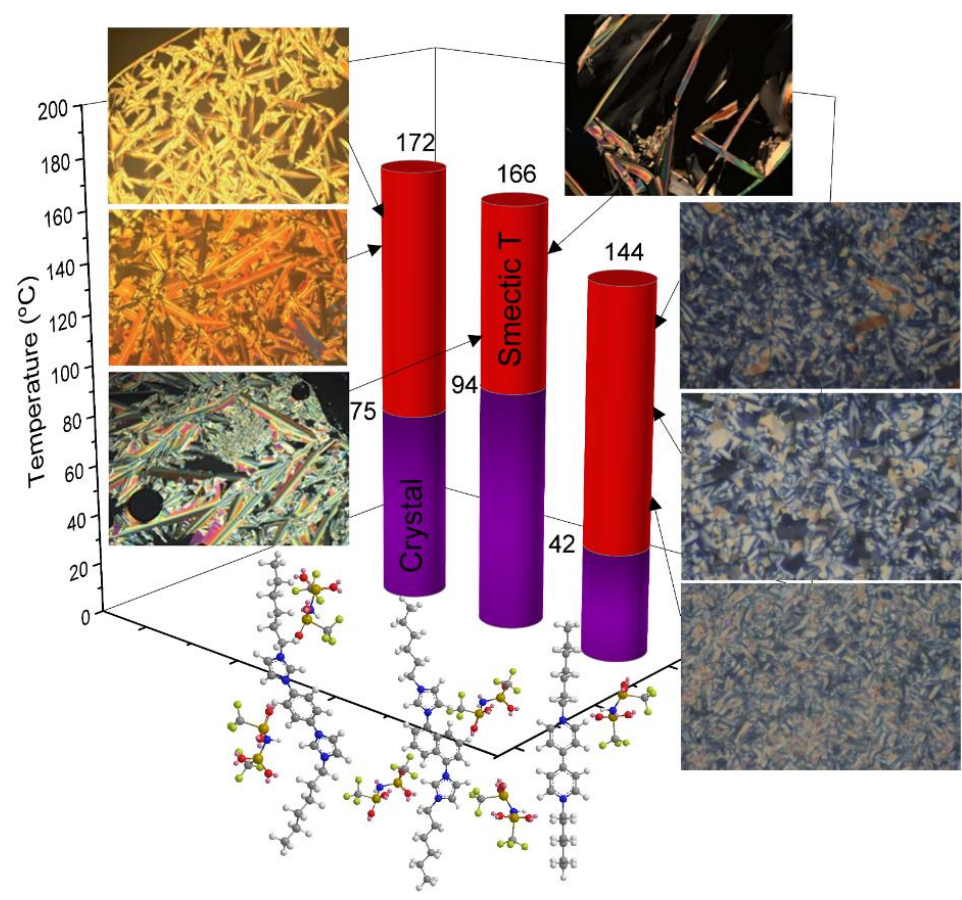

Figure 24. Thermal transitions and characteristic lancet textures from left to right (ditetradecyl (1,4-phenylene) diimidazolium bis(trifluoromethane sulfonyl)imide; dihexadecyl (1,5naphthalene) diimidazolium bis(trifluoromethane sulfonyl)imide; hexadecyl hexyl 4,4'-bipyridinium bis(trifluoromethane sulfonyl)imide. Long aliphatic chains have been shortened for clarity. The textures are from $[76,77,79]$ and are reproduced with permission. 


\section{Conclusions}

The square two-dimensional ordering is attributed to the predominance of the electrical forces observed in equal numbers of dissimilar-sized counterions over van der Walls or other types of interactions. Opposite charges were located with ones in the center and the others at the corners of a square two-dimensional lattice. In this way, the best alternation of positive and negative charges in space is secured, as dictated by the theory of the coulombic interactions. Although theoretically possible [83], there are not yet examples of either 2D lamellar tetragonal phases with non-ionic molecules or with tilted mesogens [84]. In some cases, 3D positional order exists in sublattices delimited by ionic networks. Macroscopically though, the behavior is always the same as viscous liquids. The molecules that form smectic $\mathrm{T}$ phases contain one, two, or, in one case, multiple cations comprising nitrogen [85] (quaternary ammonium, piperazinium, pyrrolidinium, piperidinium, imidazolium, bipyridinium). Assuming free rotation is possible these cations cover spherical or cylindrical volumes and large spherical anions $\mathrm{Br}^{-},[\mathrm{BF} 4]^{-},[\mathrm{PF} 6]^{-}$. Both ions are large and, in all instances, have different sizes. A substantial increase in the cation size does not seem to dramatically affect the dimensions of the tetragonal lattice, whereas this is not the case for the anions that cause swelling according to their stereochemical needs. The first [50] among several examples $[63,65,72]$ was observed for two long alkyl chains, proving that they do not cause stereochemical disruptions to the tetragonal lattice. There are also enough molecules bearing one chain and some with one long and two smaller hydroxyethyl moieties and one with four ( 1 octadecyl, 1 ethyl, 2 hydroxyethyls) but three or four long chains usually lead to columnar hexagonal or smectic A phases [86] due to the cross-section discrepancy between chains and ions.

Author Contributions: Conceptualization, M.A.; methodology, M.A. and T.K.; investigation, T.K.; resources, M.V.; data curation, M.D.; writing-original draft preparation, M.A., T.K. and M.D.; writing-review and editing, M.A. and M.D.; visualization, M.A.; supervision, M.A. and M.V.; project administration, M.V. All authors have read and agreed to the published version of the manuscript.

Funding: This research received no external funding.

Institutional Review Board Statement: Not applicable.

Informed Consent Statement: Not applicable.

Acknowledgments: This work is dedicated to Antoine Skoulios.

Conflicts of Interest: The authors declare no conflict of interest.

\section{References}

1. Goodby, J.W.; Collings, P.J.; Kato, T.; Tschierske, C.; Gleeson, H.; Raynes, P.; Vill, V. Handbook of Liquid Crystals, 8 Volume Set (Vol. 1); John Wiley \& Sons: Hoboken, NJ, USA, 2014; Volume 3, pp. 154-196.

2. De Vries, A.; Saeva, F.D. Liquid Crystals—The Fourth State of Matter; Marcel Dekker: New York, NY, USA, 1979.

3. Sluckin, T.; Dunmur, D.; Stegemeyer, H. Crystals That Flow; Taylor \& Francis: London, UK, 2004; pp. $381-385$.

4. Frank, F.C.I. Liquid crystals. On the theory of liquid crystals. Discuss. Faraday Soc. 1958, 25, 19-28. [CrossRef]

5. De Gennes, P.G.; Prost, J. The Physics of Liquid Crystals (No. 83); Oxford University Press: Oxford, UK, 1993.

6. Collings, P.J.; Hird, M. Introduction to Liquid Crystals Chemistry and Physics; CRC Press: Boca Raton, FL, USA, 2017. [CrossRef]

7. Tschierske, C. Non-conventional liquid crystals-The importance of micro-segregation for self-organization. J. Mater. Chem. 1998, 8, 1485-1508. [CrossRef]

8. Tschierske, C. Microsegregation: From Basic Concepts to Complexity in Liquid Crystal Self-Assembly. Isr. J. Chem. 2012, 52, 935-959. [CrossRef]

9. Tschierske, C. Micro-segregation, molecular shape and molecular topology-Partners for the design of liquid crystalline materials with complex mesophase morphologies Basis of a presentation given at Materials Discussion No. 4, 11-14 September 2001, Grasmere, UK. J. Mater. Chem. 2001, 11, 2647-2671. [CrossRef]

10. Paleos, C.M.; Tsiourvas, D. Thermotropic liquid crystals formed by intermolecular hydrogen bonding interactions. Angew. Chem. Int. Ed. Engl. 1995, 34, 1696-1711. [CrossRef]

11. Kato, T. Hydrogen-bonded liquid crystals: Molecular self-assembly for dynamically functional materials. In Molecular SelfAssembly Organic Versus Inorganic Approaches; Springer: Berlin/Heidelberg, Germany, 2000; pp. 95-146. [CrossRef]

12. Paleos, C.M.; Tsiourvas, D. Supramolecular hydrogen-bonded liquid crystals. Liq. Cryst. 2001, 28, 1127-1161. [CrossRef] 
13. Arkas, M.; Kitsou, I.; Gkouma, A.; Papageorgiou, M. The role of hydrogen bonds in the mesomorphic behaviour of supramolecular assemblies organized in dendritic architectures. Liq. Cryst. Rev. 2019, 7, 60-105. [CrossRef]

14. Arkas, M.; Papavasiliou, A. Effects of hydrogen-bonding on the liquid crystal-line properties of dendritic polymers. In Liquid Crystalline Polymers; Springer: Cham, Switzerland, 2016; pp. 173-194.

15. Dunmur, D.A.; Palffy-Muhoray, P. A mean field theory of dipole-dipole correlation in nematic liquid crystals. Mol. Phys. 1992, 76, 1015-1023. [CrossRef]

16. Lu, M. Liquid crystal orientation induced by Van der Waals interaction. Jpn. J. Appl. Phys. 2004, 43, 8156. [CrossRef]

17. Schmidt-Mende, L.; Fechtenkötter, A.; Müllen, K.; Moons, E.; Friend, R.H.; MacKenzie, J.D. Self-organized discotic liquid crystals for high-efficiency organic photovoltaics. Science 2001, 293, 1119-1122. [CrossRef]

18. Ganea, C.P.; Cîrcu, V.; Manaila-Maximean, D. Effect of titanium oxide nano-particles on the dielectric properties and ionic conductivity of a new smectic bis-imidazolium salt with dodecyl sulfate anion and cyanobiphenyl mesogenic groups. J. Mol. Liq. 2020, 317, 113939. [CrossRef]

19. Lubensky, T.C. Molecular description of nematic liquid crystals. Phys. Rev. A 1970, 2, 2497. [CrossRef]

20. Bisoyi, H.K.; Kumar, S. Discotic nematic liquid crystals: Science and technology. Chem. Soc. Rev. 2010, 39, 264-285. [CrossRef] [PubMed]

21. Tamaoki, N. Cholesteric liquid crystals for color information technology. Adv. Mater. 2001, 13, 1135-1147. [CrossRef]

22. McMillan, W.L. Simple molecular model for the smectic A phase of liquid crystals. Phys. Rev. A 1971, 4, 1238. [CrossRef]

23. McMillan, W.L. Simple molecular theory of the smectic C phase. Phys. Rev. A 1973, 8, 1921. [CrossRef]

24. Houssa, M.; Rull, L.F.; Romero-Enrique, J.M. Bilayered smectic phase polymorphism in the dipolar Gay-Berne liquid crystal model. J. Chem. Phys. 2009, 130, 154504. [CrossRef]

25. De Gennes, P.G.; Sarma, G. Tentative model for the smectic B phase. Phys. Lett. A 1972, 38, 219-220. [CrossRef]

26. Benattar, J.J.; Doucet, J.; Lambert, M.; Levelut, A.M. Nature of the smectic F phase. Phys. Rev. A 1979, 20, 2505. [CrossRef]

27. Gane, P.A.C.; Leadbetter, A.J.; Wrighton, P.G. Structure and correlations in smectic B, F and I phases. Mol. Cryst. Liq. Cryst. 1981, 66, 247-266. [CrossRef]

28. Livolant, F.; Levelut, A.M.; Doucet, J.; Benoit, J.P. The highly concentrated liquid-crystalline phase of DNA is columnar hexagonal. Nature 1989, 339, 724-726. [CrossRef] [PubMed]

29. Kitaigorodskii, A.I. Organic Chemical Crystallography; Consultants Bureau Enterprises: New York, NY, USA, 1961.

30. Leadbetter, A.J.; Richardson, R.M.; Carlile, C.J. The nature of the smectic E phase. J. Phys. Colloq. 1976, 37, C3-65-C3-68. [CrossRef]

31. Tsiourvas, D.; Arkas, M. Columnar and smectic self-assembly deriving from non ionic amphiphilic hyperbranched polyethylene imine polymers and induced by hydrogen bonding and segregation into polar and non polar parts. Polymer 2013, 54, 1114-1122. [CrossRef]

32. Majewska, P.; Rospenk, M.; Petrus, R.; Sobczyk, L.; Czarnik-Matusewicz, B.; Dabrowski, R. Study of packing of 4'-butyl-4isothiocyanatotolane by X-ray diffraction and infrared spectra in polarized light. Chem. Phys. Lett. 2012, 535, 56-62. [CrossRef]

33. Diele, S. On thermotropic cubic mesophases. Curr. Opin. Colloid Interface Sci. 2002, 7, 333-342. [CrossRef]

34. Canilho, N.; Kasëmi, E.; Mezzenga, R.; Schlüter, A.D. Liquid-Crystalline Polymers from Cationic Dendronized Polymer-Anionic Lipid Complexes. J. Am. Chem. Soc. 2006, 128, 13998-13999. [CrossRef]

35. Yasuda, T.; Ooi, H.; Morita, J.; Akama, Y.; Minoura, K.; Funahashi, M.; Kato, T. $\pi$-conjugated oligothiophene-based polycatenar liquid crystals: Self-organization and photoconductive, luminescent, and redox properties. Adv. Funct. Mater. 2009, 19, 411-419. [CrossRef]

36. Sagara, Y.; Yamane, S.; Mutai, T.; Araki, K.; Kato, T. A stimuli-responsive, photoluminescent, anthracene-based liquid crystal: Emission color determined by thermal and mechanical processes. Adv. Funct. Mater. 2009, 19, 1869-1875. [CrossRef]

37. Sagara, Y.; Kato, T. Mechanically induced luminescence changes in molecular assemblies. Nat. Chem. 2009, 1, 605-610. [CrossRef]

38. Demus, D.; Marzotko, D.; Sharma, N.K.; Wiegeleben, A. The polymorphism of some liquid crystalline $4^{\prime}$-n-alkyloxy-3'-nitrobiphenyl carboxylic acids. Krist. Tech. 1980, 15, 331-339. [CrossRef]

39. Levelut, A.M.; Donnio, B.; Bruce, D.W. Preliminary Communication Characterisation by X-ray diffraction of the S4 phase of some silver (I) complexes of alkoxystilbazoles. Liq. Cryst. 1997, 22, 753-756. [CrossRef]

40. Levelut, A.M.; Clerc, M. Structural investigations on 'smectic D' and related mesophases. Liq. Cryst. 1998, 24, 105-116. [CrossRef]

41. Pieranski, P.; Cladis, P.E.; Barbet-Massin, R. Experimental evidence for a hexagonal Blue Phase. J. Phys. Lett. 1985, 46, 973-977. [CrossRef]

42. Cladis, P.E.; Garel, T.; Pieranski, P. Kossel diagrams show electric-field-induced cubic tetragonal structural transition in frustrated liquid-crystal blue phases. Phys. Rev. Lett. 1986, 57, 2841. [CrossRef]

43. Pieranski, P.; Cladis, P.E. Field-induced tetragonal blue phase (BP X). Phys. Rev. A 1987, 35, 355. [CrossRef] [PubMed]

44. Ryu, J.H.; Lee, M. Liquid crystalline assembly of rod-coil molecules. In Liquid Crystalline Functional Assemblies and Their Supramolecular Structures; Springer: Berlin/Heidelberg, Germany, 2007; pp. 63-98. [CrossRef]

45. Tomašić, V.; Mihelj, T. The review on properties of solid catanionic surfactants: Main applications and perspectives of new catanionic surfactants and com-pounds with catanionic assisted synthesis. J. Dispers. Sci. Technol. 2017, 38, 515-544. [CrossRef]

46. Axenov, K.V.; Laschat, S. Thermotropic ionic liquid crystals. Materials 2011, 4, 206-259. [CrossRef]

47. Paleos, C.M. Thermotropic liquid crystals derived from amphiphilic mesogens. Mol. Cryst. Liq. Cryst. Sci. Technol. Sect. A Mol. Cryst. Liq. Cryst. 1994, 243, 159-183. [CrossRef] 
48. Alvarez Fernandez, A.; Kouwer, P.H. Key developments in ionic liquid crystals. Int. J. Mol. Sci. 2016, 17, 731. [CrossRef]

49. Taubert, A.; Kapernaum, N.; Lange, A.; Ebert, M.; Grunwald, M.A.; Haege, C.; Laschat, S. Current Topics in Ionic Liquid Crystals. ChemPlusChem 2021, 86, 1-39. [CrossRef]

50. Alami, E.; Levy, H.; Zana, R.; Weber, P.; Skoulios, A. A new smectic mesophase with two-dimensional tetragonal symmetry from dialkyldimethylammonium bromides: ST. Liq. Cryst. 1993, 13, 201-212. [CrossRef]

51. Przedmojski, J.; Dynarowicz-lqtka, P. X-ray investigation of dialkyldimethylammonium bromides. Phase Transit. A Multinatl. J. 1999, 70, 133-146. [CrossRef]

52. Arkas, M.; Yannakopoulou, K.; Paleos, C.M.; Weber, P.; Skoulios, A. The mesomorphic behaviour of cyanopropylalkyldimethylammonium bromides. Liq. Cryst. 1995, 18, 563-569. [CrossRef]

53. Arkas, M.; Paleos, C.M.; Skoulios, A. Crystal and liquid crystal behaviour of N-cyanoalkyl-N-alkyl-N, N-dimethylammonium bromides: Role of the dipole interactions of the cyano groups. Liq. Cryst. 1997, 22, 735-742. [CrossRef]

54. Paleos, C.M.; Arkas, M.; Skoulios, A. Mesomorphic character of quaternary ammonium salts affected by secondary hydrogen bonding interactions. Mol. Cryst. Liq. Cryst. Sci. Technol. Sect. A Mol. Cryst. Liq. Cryst. 1998, 309, 237-250. [CrossRef]

55. Arkas, M.; Tsiourvas, D.; Paleos, C.M.; Skoulios, A. Smectic mesophases from dihydroxy derivatives of quaternary alkylammonium salts. Chem.-A Eur. J. 1999, 5, 3202-3207. [CrossRef]

56. Guillon, D.; Skoulios, A.; Benattar, J.J. Volume and X-ray diffraction study of terephthal-bis-4, n-decylaniline (TBDA). J. Phys. 1986, 47, 133-138. [CrossRef]

57. Song, B.; Shang, S.; Song, Z. Solution behavior and solid phase transitions of quaternary ammonium surfactants with head groups decorated by hydroxyl groups. J. Colloid Interface Sci. 2012, 382, 53-60. [CrossRef]

58. Tanford, C. Micelle shape and size. The Journal of Physical Chemistry, 76, 3020-3024. Tanford, C. Micelle shape and size. J. Phys. Chem. 1972, 76, 3020-3024. [CrossRef]

59. Paleos, C.; Arkas, M.; Seghrouchni, R.; Skoulios, A. Smectic mesophases from quaternary amphiphilic ammonium salts functionalized with interacting endgroups. Mol. Cryst. Liq. Cryst. Sci. Technol. Sect. A Mol. Cryst. Liq. Cryst. 1995, 268, 179-182. [CrossRef]

60. Arkas, M.; Kitsou, I.; Petrakli, F. Mimicking the behaviour of rigid rod molecules. Smectic H liquid crystals from amphiphilic quaternary ammonium salts. Liq. Cryst. 2018, 45, 70-83. [CrossRef]

61. Doucet, J.; Levelut, A.M.; Lambert, M. Polymorphism of the mesomorphic compound terephthal-bis-butylaniline (TBBA). Phys. Rev. Lett. 1974, 32, 301. [CrossRef]

62. Alami, E.; Levy, H.; Zana, R.; Skoulios, A. Alkanediyl-. alpha.,. omega.-bis (dimethylalkylammonium bromide) surfactants. 2. Structure of the lyotropic mesophases in the presence of water. Langmuir 1993, 9, 940-944. [CrossRef]

63. Fuller, S.; Shinde, N.N.; Tiddy, G.J.; Attard, G.S.; Howell, O. Thermotropic and lyotropic mesophase behavior of amphitropic diammonium surfactants. Langmuir 1996, 12, 1117-1123. [CrossRef]

64. Jurasin, D.; Pustak, A.; Habus, I.; Smit, I.; Filipovic-Vincekovic, N. Polymorphism and mesomorphism of oligomeric surfactants: Effect of the degree of oligomerization. Langmuir 2011, 27, 14118-14130. [CrossRef]

65. Tittarelli, F.; Masson, P.; Skoulios, A. Structural compatibility of smectic sub-layers: Liquid crystals from oxynitrostilbene derivatives of dialkyldimethylammonium bromides. Liq. Cryst. 1997, 22, 721-726. [CrossRef]

66. Zhou, M.; Zhang, J.; Wang, S.; Boyer, D.; Guo, H.; Li, W.; Wu, L. Lat Laterally substituted ionic liquid crystals and the resulting rheological behaviorerally substituted ionic liquid crystals and the resulting rheological behavior. Soft Matter 2012, 8, 7945-7951. [CrossRef]

67. Iwamoto, K.; Ohnuki, Y.; Sawada, K.; Senō, M. Solid-solid phase transitions of long-chain n-alkyltrimethylammonium halides. Mol. Cryst. Liq. Cryst. 1981, 73, 95-103. [CrossRef]

68. Shimizu, J.; Nogami, T.; Mikawa, H. Phase transition of quaternary alkyl halide salts of diazabicyclo [2.2. 2] octane. Solid State Commun. 1985, 54, 1009-1011. [CrossRef]

69. Ohta, K.; Sugiyama, T.; Nogami, T. A smectic T phase of 1, 4-dialkyl-1, 4-diazoniabicyclo [2.2.2] octane dibromides. J. Mater. Chem. 2000, 10, 613-616. [CrossRef]

70. Nikokavoura, A.; Tsiourvas, D.; Arkas, M.; Sideratou, Z.; Paleos, C.M. Thermotropic liquid crystalline behaviour of piperazinium and homopiperazinium alkylsulphates. Liq. Cryst. 2002, 29, 1547-1553. [CrossRef]

71. Nikokavoura, A.; Tsiourvas, D.; Arkas, M.; Sideratou, Z.; Paleos, C.M. Liquid crystals derived from multi-cationic azamacrocyclic alkylsulphates. Liq. Cryst. 2004, 31, 207-213. [CrossRef]

72. Lava, K.; Binnemans, K.; Cardinaels, T. Piperidinium, piperazinium and morpholinium ionic liquid crystals. J. Phys. Chem. B 2009, 113, 9506-9511. [CrossRef]

73. Goossens, K.; Lava, K.; Nockemann, P.; Van Hecke, K.; Van Meervelt, L.; Driesen, K.; Cardinaels, T. Pyrrolidinium ionic liquid crystals. Chem.-A Eur. J. 2009, 15, 656-674. [CrossRef] [PubMed]

74. Xu, F.; Matsubara, S.; Matsumoto, K.; Hagiwara, R. Effects of alkyl chain length on properties of N-alkyl-N-methylpyrrolidinium fluorohydrogenate ionic liquid crystals. J. Fluor. Chem. 2012, 135, 344-349. [CrossRef]

75. Goossens, K.; Lava, K.; Nockemann, P.; Van Hecke, K.; Van Meervelt, L.; Pattison, P.; Cardinaels, T. Pyrrolidinium ionic liquid crystals with pendant mesogenic groups. Langmuir 2009, 25, 5881-5897. [CrossRef] [PubMed]

76. Noujeim, N.; Samsam, S.; Eberlin, L.; Sanon, S.H.; Rochefort, D.; Schmitzer, A.R. Mesomorphic and ion-conducting properties of dialkyl (1, 4-phenylene) diimidazolium salts. Soft Matter 2012, 8, 10914-10920. [CrossRef] 
77. Do, T.D.; Schmitzer, A.R. Intramolecular Diels Alder reactions in highly organized imidazolium salt-based ionic liquid crystals. RSC Adv. 2015, 5, 635-639. [CrossRef]

78. Tschierske, C. Star-shaped oligobenzoates with a naphthalene chromophore as potential semiconducting liquid crystal materials? J. Mater. Chem. 2012, 18, 2995-3003. [CrossRef]

79. Bhowmik, P.K.; Noori, O.; Chen, S.L.; Han, H.; Fisch, M.R.; Robb, C.M.; Martinez-Felipe, A. Ionic liquid crystals: Synthesis and characterization via NMR, DSC, POM, X-ray diffraction and ionic conductivity of asymmetric viologen bistriflimide salts. J. Mol. Liq. 2021, 328, 115370. [CrossRef]

80. Yang, M.; Stappert, K.; Mudring, A.V. Bis-cationic ionic liquid crystals. J. Mater. Chem. C 2014, 2, 458-473. [CrossRef]

81. Wu, B.P.; Pang, M.L.; Tan, T.F.; Meng, J.B. The $\mathrm{T}^{\prime}$ phase and its 'sandwich-like layer'structure as shown by ionic liquid crystals containing a biphenyl ester-based rigid-core modified by 3-alkylimidazolium salts. Liq. Cryst. 2012, 39, 579-594. [CrossRef]

82. Tripathi, C.S.P.; Leys, J.; Losada-Pérez, P.; Lava, K.; Binnemans, K.; Glorieux, C.; Thoen, J. Adiabatic scanning calorimetry study of ionic liquid crystals with highly ordered crystal smectic phases. Liq. Cryst. 2013, 40, 329-338. [CrossRef]

83. Józefowicz, W.; Longa, L. Frustration in smectic layers of polar Gay-Berne systems. Phys. Rev. E 2007, 76, 011701. [CrossRef]

84. Berardi, R.; Orlandi, S.; Zannoni, C. Molecular dipoles and tilted smectic formation: A Monte Carlo study. Phys. Rev. E 2003, 67, 041708. [CrossRef] [PubMed]

85. Binnemans, K. Ionic liquid crystals. Chem. Rev. 2005, 105, 4148-4204. [CrossRef] [PubMed]

86. Goossens, K.; Lava, K.; Bielawski, C.W.; Binnemans, K. Ionic liquid crystals: Versatile materials. Chem. Rev. 2016, $116,4643-4807$. [CrossRef] [PubMed] 